\title{
Germ cell tumors of the gonads: a selective review emphasizing problems in differential diagnosis, newly appreciated, and controversial issues
}

\author{
Thomas M Ulbright \\ Department of Pathology \& Laboratory Medicine, Clarian Health Partners and Indiana University School of \\ Medicine, Indianapolis, IN, USA
}

\begin{abstract}
Gonadal germ cell tumors continue to be the cause of diverse, diagnostically challenging issues for the pathologist, and their correct resolution often has major important therapeutic and prognostic implications. They are academically interesting because of the biological diversity exhibited in the two gonads and variation in frequency of certain neoplasms. The most dramatic examples of the latter are the frequency of dermoid cyst in the ovary compared to the testis and the reverse pertaining to embryonal carcinoma. Within the teratoma group, there is strong evidence that ovarian and prepubertal testicular teratomas are derived from benign germ cells, a pathogenesis that likely applies also to the rare dermoid cysts and uncommon epidermoid cysts of the testis. In contrast, postpubertal testicular teratomas derive from malignant germ cells, specifically representing differentiation within a preexistent nonteratomatous cancer. As expected, given the foregoing, teratomas in boys are clinically benign, whereas in postpubertal males they are malignant, independent of their degree of immaturity. On the other hand, immaturity is an important finding in ovarian teratomas, irrespective of age, although its significance in children has recently been challenged. It is usually recognized on the basis of embryonic-appearing neuroepithelium, which shows mitotic activity and apoptosis in contrast to differentiated neuroepithelial tissues, which may occur in mature ovarian teratomas. Rarely it is based on the presence of cellular, mitotically active glial tissue. Fetal-type tissues alone are not sufficient for a diagnosis of immature teratoma. Further differences between the teratomatous tumors in the two gonads are the relative frequency of monodermal teratomas in the ovary in contrast to the testis, where only one subset, carcinoids, is seen with any frequency. When uncommon somatic-type malignancies (usually squamous cell carcinoma) occur in mature cystic teratomas of the ovary, this is a de novo form of malignant transformation; similar tumors in the testis, a very rare event, represent overgrowth of teratomatous elements that originated from malignant, nonteratomatous germ cell tumors and, therefore, had previously undergone malignant transformation. Germinomas may have several unusual features in each gonad; these include microcystic arrangements that suggest yolk sac tumor, tubular patterns that mimic Sertoli cell tumor, apparent increased cytological atypia that causes concern for embryonal carcinoma, and prominent syncytiotrophoblast giant cells that suggest choriocarcinoma. Awareness of these variants, good technical preparations, the retained typical cytological features of germinoma cells, and the judicious use of tailored panels of immunohistochemical stains resolve these dilemmas in virtually all instances. Two aspects of germinomas are unique to the testis. Firstly, intertubular growth of small seminomas may cause them to be overlooked. Secondly, the distinctive spermatocytic seminoma occurs only in the testis. A newly recognized aspect of this tumor is the propensity for some to be relatively monomorphic, making them apt to be mistaken for usual seminoma or embryonal carcinoma, although the characteristic polymorphic appearance in some foci, absence of intratubular germ cell neoplasia, unclassified type, and immunohistochemical stains should prevent this error. Cytoplasmic membrane immunoreactivity for placental alkaline phosphatase and CD117, with usual negativity for AE1/AE3 cytokeratins, is helpful in the diagnosis of germinoma. The recently described marker, OCT3/4, a nuclear transcription factor, is especially helpful in the differential of germinoma and embryonal carcinoma with other neoplasms. Yolk sac tumor continues to be confused occasionally with clear cell carcinoma of the ovary. Glandular ('endometrioidlike') yolk sac tumors mimic endometrioid carcinomas; predominant or pure hepatoid yolk sac tumors cause concern for metastatic hepatocellular carcinoma or, in the ovary, primary hepatoid carcinoma, and solid
\end{abstract}

Correspondence: Dr TM Ulbright, MD, Department of Pathology, Indiana University Hospital—Room 3465, 550 N. University Blvd., Indianapolis, IN 46202-5280, USA.

E-mail: tulbrigh@iupui.edu

Received and accepted 29 August 2004 
patterns, especially in limited samplings, may be misinterpreted as germinoma. The usually younger age of patients with yolk sac tumors helps with the differential considerations with the nongerm cell tumors, as do other clinical and microscopic features and selected immunohistochemical stains. Choriocarcinoma is rare in both gonads, and those in the ovary must be distinguished from metastatic tumors of placental origin. Syncytiotrophoblast cells alone, admixed with other forms of germ cell tumor, still are confused with choriocarcinoma, but this phenomenon, which is much more frequent than choriocarcinoma, lacks the plexiform arrangement of different trophoblast cell types that typifies the latter. Mixed germ cell tumors (which may show almost any combination of components) are common in the testis but rare in the ovary. A separately categorized, rare form of mixed germ cell tumor seen in both gonads is the polyembryoma. It is perhaps the most photogenic of all gonadal germ cell tumors and is also intriguing because of its distinctive, organized arrangement of yolk sac tumor and embryonal carcinoma elements and recapitulation of very early embryonic development, even to the extent of having in its fundamental unit, the embryoid body, a miniature yolk sac, and amniotic cavity. These tumors, which are constituted by innumerable embryoid bodies, almost always contain teratomatous glands in minor amounts, and one way of viewing the polyembryoma is to consider it the most immature form of teratoma. Embryoid bodies are also common as a minor component of many mixed germ cell tumors, particularly in the testis, and the diffuse embryoma is another variant that has a particular arrangement of yolk sac tumor and embryonal carcinoma elements. Regression of gonadal germ cell tumors is a phenomenon restricted to the testis, for unknown reasons. These so-called 'burnt-out' germ cell tumors can be recognized by a distinctive constellation of findings, including sometimes minor foci of residual recognizable germ cell neoplasia, a well-defined zone of scarring (often having residual ghost tubules), associated lymphoplasmacytic infiltrate, intratubular calcification and, in about $50 \%$, of in situ germ cell neoplasia. Modern Pathology (2005) 18, S61-S79. doi:10.1038/modpathol.3800310

Keywords: ovary; testis; gonads; germ cell tumors; teratoma; germinoma

The entire topic of gonadal germ cell tumors is a vast one, and accordingly, because of space constraints, the emphasis here is necessarily on selected difficult, newly appreciated, or controversial areas. One of the themes of this review will be that even though germ cell tumors in the gonads are similar morphologically, there are still striking overall contrasts; for example, the high frequency of dermoid cyst in the ovary and its extreme rarity in the testis; the different implications of immaturity of teratomas in the two gonads and the biologic differences between ovarian and testicular teratomas; the restriction of one germ cell tumor, the spermatocytic seminoma, to the testis; the much greater frequency of embryonal carcinoma in the testis compared to the ovary; and the occasional development of spontaneous regression in testicular but not ovarian germ cell tumors.

Gonadal teratomas are considered first, mainly from the conceptual viewpoint concerning their different pathogenesis and malignant potential in the ovary and the testis, as the microscopic diagnosis of teratomas is usually not a problem. The important issue of grading of immature ovarian teratomas is also discussed. Unusual patterns of germinoma (testicular seminoma and ovarian dysgerminoma) and yolk sac tumor and the various diagnostic problems posed by them are covered next, as are helpful findings for the diagnosis of embryonal carcinoma and the features of the distinctive polyembryoma. Brief note is also made of choriocarcinoma, a rare neoplasm in either gonad. Space does not allow for consideration of lesions of intersex, but the occasional origin of germ cell tumors from dysgenetic gonads with gonadoblastoma is always to be remembered. The phenotypic females with the androgen insensitivity syndrome also are prone to develop germ cell tumors from the cells of intratubular germ cell neoplasia of the unclassified type (IGCNU) that may occur in the immature seminiferous tubules of their ectopic testes.

\section{Teratoma}

The relative proportion of teratoma among the germ cell tumors is quite different in the two gonads, with about $95 \%$ of ovarian germ cell tumors represented by pure teratoma, ${ }^{1,2}$ but only about $4 \%$ of testicular germ cell tumors ${ }^{3,4}$ (Table 1). Most teratomatous elements in the testis occur as a component of mixed germ cell tumors, which represent about one-third of all testicular germ cell tumors and contain teratoma in about $50 \%$ of the cases. ${ }^{3,4}$ On the other hand, mixed germ cell tumors of the ovary are uncommon, representing less than $1 \%$ of ovarian germ cell tumors. ${ }^{5,6}$

In comparing gonadal teratomas, the behavior in the testis, but less so in the ovary, depends to a great extent on whether the patient is prepubertal or postpubertal. Prepubertal testicular teratomas are benign, yet their morphologically similar counterparts in the postpubertal testis are malignant, whether mature or immature. This discussion will focus first on a comparison of pure, mature teratomas of the ovary and testis in postpubertal patients, followed by a similar consideration of pure 
Table 1 Relative proportions of histologic types of germ cell tumors in the ovary and testis

\begin{tabular}{lcc}
\hline Histologic type & $\begin{array}{c}\text { Proportion in the } \\
\text { ovary (\%) }\end{array}$ & $\begin{array}{c}\text { Proportion in the } \\
\text { testis (\%) }\end{array}$ \\
\hline $\begin{array}{l}\text { Teratoma } \\
\begin{array}{l}\text { Dysgerminoma/ } \\
\text { seminoma }\end{array}\end{array}$ & 95 & 4 \\
$\begin{array}{l}\text { Yolk sac tumor } \\
\text { Embryonal }_{\text {carcinoma }}\end{array}$ & 1 & 50 \\
$\begin{array}{l}\text { Choriocarcinoma } \\
\text { Polyembryoma }\end{array}$ & 0.2 & 1 \\
$\begin{array}{l}\text { Mixed germ cell } \\
\text { tumor }\end{array}$ & $<0.1$ & 10 \\
& $<0.1$ & 0.3 \\
& $<1$ & $<1$ \\
\end{tabular}

${ }^{\mathrm{a}}$ These figures refer to tumors of pure histologic type.

mature teratomas of the two gonads in prepubertal patients. This will highlight fundamental differences but also some similarities in the two gonads.

\section{Mature, postpubertal gonadal teratomas}

Teratomas in the ovary occur over a broad age range, albeit with a proclivity for the reproductive years, ${ }^{6}$ whereas those in the postpubertal testis are almost always restricted to patients between 20 and 40 years of age. $^{7-9}$ DNA quantification shows that mature ovarian teratomas are diploid, and cytogenetic study demonstrates that they almost always have a normal 46,XX karyotype, ${ }^{10,11}$ whereas mature teratomas of the postpubertal testis are hyperdiploid to hypotriploid with complex cytogenetic abnormalities including invariable $12 \mathrm{p}$ amplification, often in the form of an isochromosome [i (12p)]. ${ }^{12-16}$ Molecular genetic analysis has also shown that mature ovarian teratomas are usually homozygous for polymorphic markers, ${ }^{17}$ indicating that they derive most often from a germ cell that has completed meiosis I but not meiosis II, a conclusion supported by cytogenetic analysis. ${ }^{11}$ When heterozygosity does occur, it predictably is in loci that tend to be located distant from the centromere-that is, in genes most susceptible to crossing over at the metaphase plate of meiosis $\mathrm{I}^{10,18}$ On the other hand, genetic analysis has also shown that the teratomatous elements in postpubertal mixed germ cell tumors of the testis have strikingly parallel allelic losses compared to the nonteratomatous components of the same tumor, ${ }^{19}$ supporting the concept that postpubertal teratoma of the testis usually derives from other forms of germ cell tumor. The most important contrasting feature, however, between mature ovarian and postpubertal testicular teratomas is that the former have a uniformly benign clinical course, whereas metastases, often of nonteratomatous germ cell tumor types, occur in 20$40 \%$ of the latter, ${ }^{7-9}$ corroborating the observation of Tanner ${ }^{20}$ in 1922.
There are also differences in the gross and light microscopic features of mature ovarian and postpubertal testicular teratomas, with the ovarian tumors usually being predominantly cystic (the familiar dermoid cyst) in contrast to the predominant solid appearance of the testicular tumors. On microscopic examination, the mature ovarian teratomas have a well-organized, arrangement of tissues that often duplicates the relationships seen in normal organs, for instance pilosebaceous structures and sweat glands within squamous epitheliallined 'dermis' or respiratory epithelium encircled by smooth muscle and cartilage. The elements within these 'organoid' tissues, furthermore, lack cytological atypia and have scant mitotic activity that is mostly confined to the normal proliferative zones of the organs they replicate. On the other hand, postpubertal testicular teratomas have a more disordered arrangement (Figure 1), frequently show significant cytological atypia (Figure 2), and may have widespread mitotic activity. Additionally, the seminiferous tubules adjacent to these tumors show IGCNU in approximately $90 \%$ of the cases, ${ }^{21}$ and there is often widespread testicular atrophy with impaired to absent spermatogenesis.

A spectrum of different types of tissues may be identified in mature teratomas of both the ovary and testis, although there are some notable differences in their frequency in the two gonads. For instance, choroid plexus and thyroid tissue are common in ovarian teratomas, and pituitary tissue may also be seen on occasion, ${ }^{22}$ rarely giving rise to functioning prolactinomas. ${ }^{23}$ These tissue types are infrequent (choroid plexus) to rare (thyroid) to virtually nonexistent (pituitary) in testicular teratomas. Paradoxically, prostatic tissue infrequently occurs in ovarian teratomas but is even rarer in the testis. ${ }^{24,25} \mathrm{Me}-$ ninges are a described but rare finding in testicular teratomas ${ }^{26}$ with one reported case of a microcystic meningioma of teratomatous origin. ${ }^{27}$

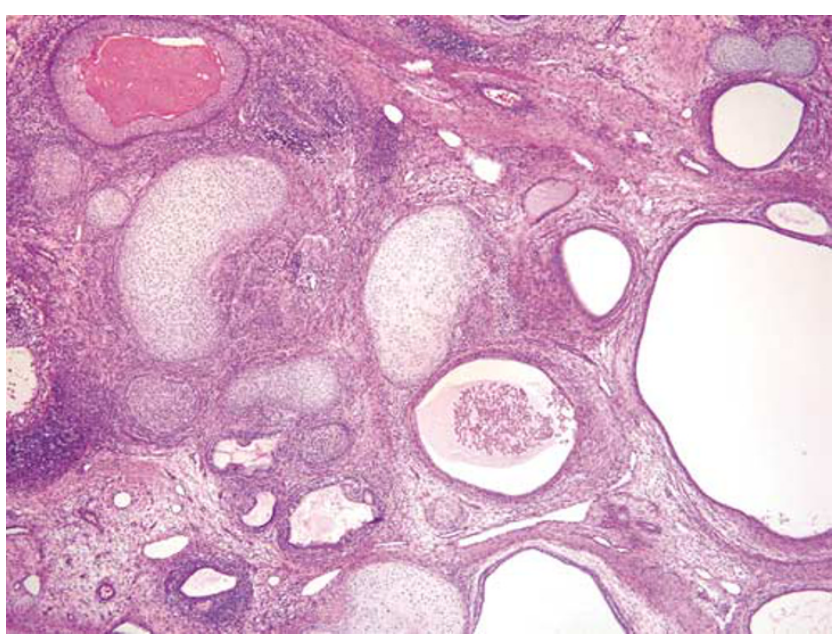

Figure 1 Postpubertal testicular teratoma with a disordered arrangement of elements. 


\section{Mature, prepubertal gonadal teratomas}

A comparison of mature prepubertal gonadal teratomas, in contrast to the situation with the postpubertal examples, shows striking similarities between those in the ovary and the testis. Prepubertal testicular teratomas represent approximately $30 \%$ of testicular germ cell tumors in children, ${ }^{28}$ are typically pure, have a diploid DNA content ${ }^{29}$ and normal 46,XY karyotype, ${ }^{30}$ show normal findings by comparative genomic hybridization studies, ${ }^{31}$ often have organoid tissue arrangements (Figure 3), lack cytological atypia and widespread mitotic activity, are not associated with IGCNU, ${ }^{21}$ and are clinically benign. ${ }^{28}$ These features are all similar to those mentioned above for mature ovarian teratomas. Germ cells in the seminiferous tubules adjacent to pediatric teratomas may appear somewhat atypical, with occasional cells showing nuclear enlargement or multinucleation (Figure 4), but

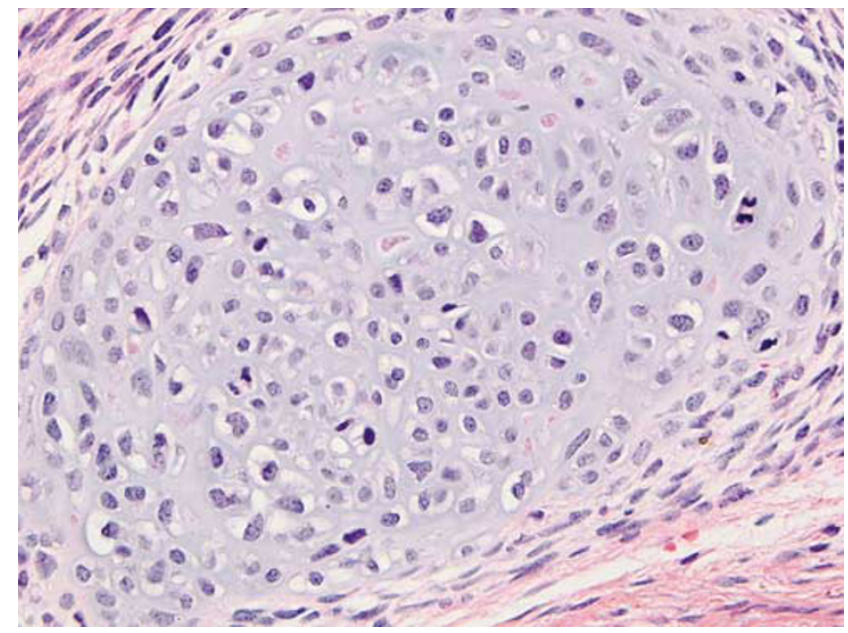

Figure 2 Malignant cytological features in the cartilaginous component of a postpubertal testicular teratoma. Note mitotic figure (upper right).

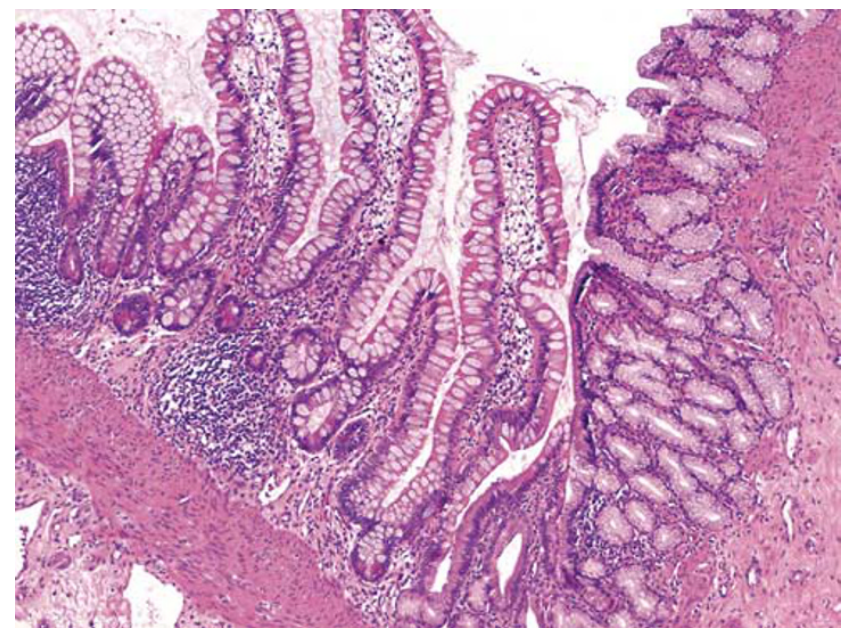

Figure 3 Organoid replication of small intestinal mucosa and gastric pyloric-type mucosa in a prepubertal testicular teratoma. these features are different from the seminoma-like cells of IGCNU and have been interpreted as a reactive phenomenon based on similar changes in germ cells adjacent to sex cord-stromal tumors in the pediatric testis. $^{32}$ There are occasional exceptions, with prepubertal testicular teratomas exhibiting adjacent IGCNU, ${ }^{33}$ similar to the situation with gonadal dysgenesis in children, but these remain outliers.

\section{Dermoid and epidermoid cysts of the testis}

Two examples of postpubertal testicular teratomas that are analogous to mature ovarian teratomas and prepubertal testicular teratomas are dermoid and epidermoid cysts, although the pathogenesis of the latter, whether a neoplasm or not, is controversial. The loss of heterozygosity in some epidermoid cysts, however, provides support for its teratomatous nature. ${ }^{34}$ The rare testicular dermoid cyst shares with the common ovarian dermoid the usual presence of grossly identifiable hair within a cystic tumor $^{20}$ and, on microscopic examination, the organoid replication of skin and absence of cytological atypia or widespread mitotic activity. It also lacks adjacent IGCNU and the association with testicular atrophy, instead usually occurring in a testis with normal spermatogenesis. ${ }^{35}$ The typical arrangement of pilosebaceous units to an epidermal surface is a necessary feature for the diagnosis of testicular dermoid cyst. The presence of a lipogranulomatous reaction in the testicular parenchyma is characteristic, helpful in diagnosis and is due to the leakage of oily, sebaceous gland secretion from the cyst into the adjacent testis. Other, noncutaneous elements may be present in testicular dermoids, as in the ovary. Sometimes these elements also have an organoid arrangement, for instance showing a

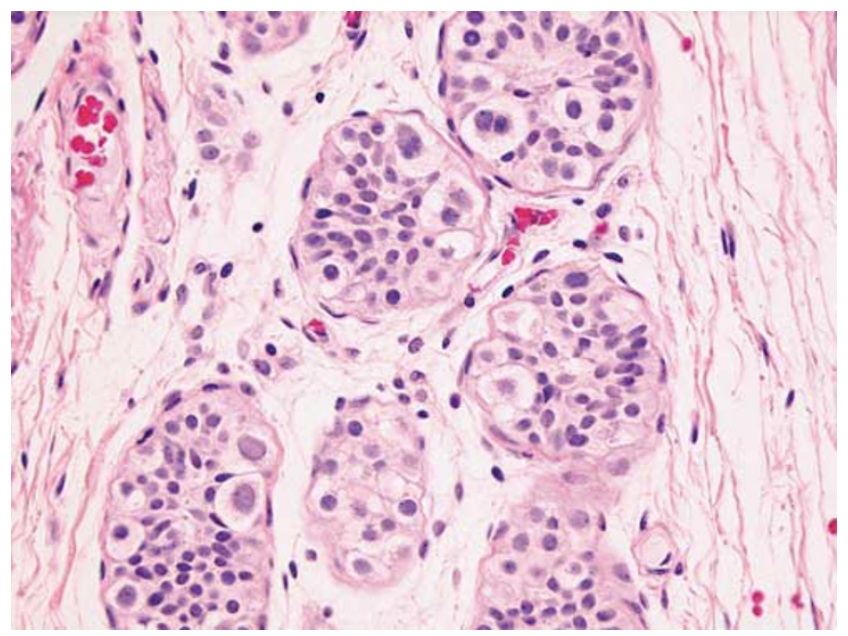

Figure 4 Multinucleation and focal nuclear enlargement in the germ cells adjacent to a prepubertal testicular teratoma. These cells lack the vesicular nuclei with prominent nucleoli of intratubular germ cell neoplasia, unclassified type. 
reiteration of small bowel mucosa and submucosa. Epidermoid cyst represents about $1 \%$ of testicular tumors and is rare in the ovary. ${ }^{36,37}$ Whether these lesions are neoplasms or not remains a topic of debate, although some show loss of heterozygosity for certain chromosomal loci, supporting a neoplastic pathogenesis. ${ }^{34}$ Epidermoid cysts lack atypia and mitotic activity, and the testicular cases, like dermoid cyst, are not associated with IGCNU. ${ }^{21,38}$ Dermoid and epidermoid cysts are benign. ${ }^{21,35,36}$

\section{Histogenetic considerations in gonadal teratomas}

These differences in gonadal teratomas can be explained by a pathogenetic model wherein ovarian teratomas, prepubertal testicular teratomas, and dermoid/epidermoid cysts are derived from benign germ cells. The generally homozygous nature of ovarian teratomas further supports a parthenogenetic-like pathogenesis. On the other hand, the usual postpubertal testicular teratoma is derived from a malignant germ cell (IGCNU) that gives rise to a nonteratomatous form of germ cell tumor, which, in turn, differentiates to form teratomatous elements. This pathogenesis is supported by the strikingly parallel patterns of allelic loss in teratomas of the postpubertal testis and the other germ cell tumor types that accompany them. ${ }^{19}$ This explains the association of pure testicular teratoma in postpubertal patients with IGCNU and metastases of nonteratomatous type and the uncommon occurrence of postpubertal testicular teratoma without other germ cell tumor types. In this model (Figure 5), therefore, malignant transformation in the example of postpubertal testicular teratomas occurs prior to teratomatous differentiation ('preteratomatous' malignant transformation). On the other hand, for those rare ovarian teratomas with malignant elements, ${ }^{39,40}$ malignant transformation occurs after the development of the teratoma ('post-teratomatous' malignant transformation). This applies to those dermoid cysts that develop malignant somatic neoplasms, most commonly squamous cell carcinoma ${ }^{41,42}$ but rarely other types such as malignant melanoma, ${ }^{43}$ adenocarcinoma ${ }^{24,44}$ and various forms of sarcoma, ${ }^{42} \mathrm{a}$ phenomenon seen in $0.2-1.4 \%$ of mature ovarian teratomas. ${ }^{39,40}$ The homozygous nature of the malignant elements in these cases, which is similar to the benign elements, supports derivation of the former from the latter, ${ }^{17}$ as do similar cytogenetic changes in the two components. ${ }^{45}$ Additionally, immaturity in ovarian teratomas can be seen in a similar light as representing clones of malignant neuroepithelium that develop within a pre-existing teratoma.

\section{Immature teratoma and selected monodermal teratomas}

Immaturity, usually manifest as immature neuroepithelium but sometimes additionally or rarely

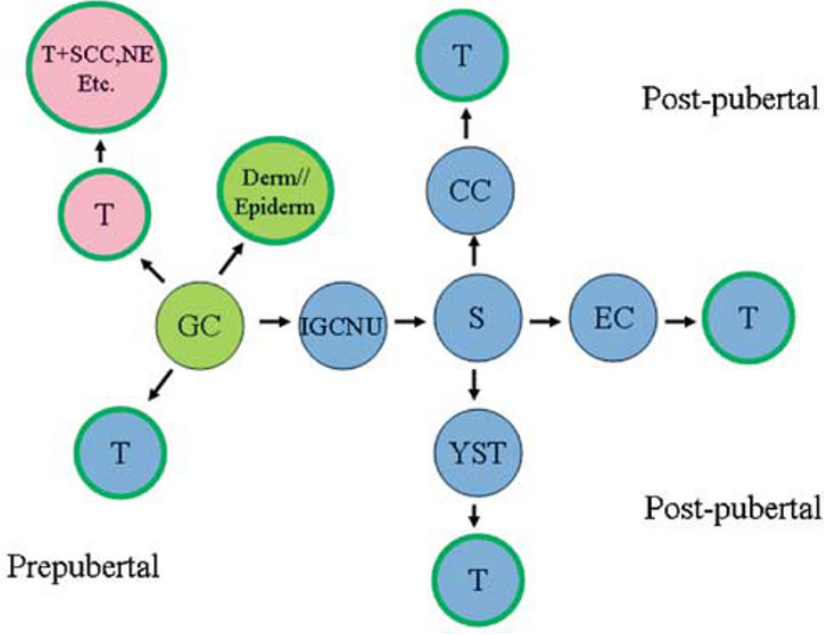

Figure 5 Histogenetic model for the development of teratomas of the ovary, prepubertal testis, and postpubertal testis. Ovarian pathway in pink; testicular pathway in blue, and common pathway in light green. Abbreviations: CC-choriocarcinoma; Derm-dermoid cyst; EC-embryonal carcinoma; Epidermepidermoid cyst; GC-germ cell; IGCNU-intratubular germ cell neoplasia, unclassified type; NE-immature neuroepithelium; S-seminoma; SCC-squamous cell carcinoma; T-teratoma; YST-yolk sac tumor.

solely as cellular, mitotically active glia, is important to assess in ovarian teratomas. Semiquantification of the amount of neuroepithelium correlates with survival in ovarian immature teratoma, at least in adult patients, and is the basis for grading of these tumors. ${ }^{46-48}$ Those with less than one lower power field $(\times 4)$ of immature neuroepithelium on the slide with the greatest amount of such tissue (grade 1) have a survival of at least $95 \%$, whereas greater amounts of immature neuroepithelium (grades 2 and 3), with modern treatment, have a lower overall survival (approximately 85\%). ${ }^{48}$ These correlations may not apply, however, to immature teratomas of the ovary in children since recent work has shown a good outcome with surgery alone, regardless of the degree of immaturity, in these cases. ${ }^{49,50}$ Immature ovarian teratomas are associated with gliomatosis peritonei, a favorable prognostic finding if composed of completely mature tissues, ${ }^{51,52}$ with the seemingly unexpected recent discovery, using molecular methods, that these glial 'implants' are not tumor derived but represent teratoma-induced metaplasia of submesothelial cells. ${ }^{53,54}$ On the other hand, immaturity in postpubertal testicular teratomas has no established significance. The different importance of immature elements in these two forms of teratoma can also be rationalized by the pathogenetic model discussed previously (Figure 5). Since ovarian teratomas are derived from benign germ cells, immature elements represent the evolution of a malignant clone, and it is therefore logical that the prognosis relates to the amount of this component. This clonal concept is supported by the demonstration of small foci of immature neuroepithelium, of 
S66

no apparent clinical significance, in otherwise typical ovarian dermoid cysts, as well as occasional cases of immature teratoma that develop subsequent to excision of an ovarian dermoid. ${ }^{55}$ The lack of 12p amplification in immature ovarian teratomas, in contrast to its presence in other types of malignant ovarian germ cell tumor, is also in keeping with this hypothesis by supporting a fundamentally different pathogenesis for immature ovarian teratoma compared to other malignant ovarian germ cell tumors. ${ }^{56}$ In fact, immature ovarian teratoma usually shows only relatively minor cytogenetic abnormalities, in contrast to the other forms of malignant ovarian germ cell tumor, with increasing abnormalities as the grade of the immaturity becomes higher. ${ }^{57}$ On the other hand, since testicular teratomas in postpubertal patients represent the end stage of a differentiation process from other types of malignant germ cell tumor, it is immaterial if 'immaturity' is present. Immaturity, in a sense, is 'trumped' by the invasive malignant germ cell tumor from which the teratoma derived in the postpubertal testis.

When considering possible immaturity in ovarian teratomas, it is important not to mistake cellular but differentiated neural elements, such as those resembling cerebellar granular cells, for immature elements. Immature neural elements should have a somewhat vesicular chromatin and show apoptosis and mitotic activity (Figure 6), in contrast to end stage differentiated neural elements. Such fully differentiated neural cells have a uniformly dense chromatin without mitotic activity or apoptosis. It is also important not to consider fetal-type tissue, such as cartilage, evidence of immaturity. The diagnosis of immaturity requires tissue with an embryonal appearance, almost always neuroepithelium, as noted earlier.

Overgrowth of immature neural elements in either ovarian or testicular teratomas is the basis for the diagnosis of primitive neuroectodermal tumor (PNET) (Figure 7). Ovarian PNETs have an aggressive clinical course and poor prognosis; ${ }^{58,59}$ on the other hand, the prognosis of PNET in postpubertal

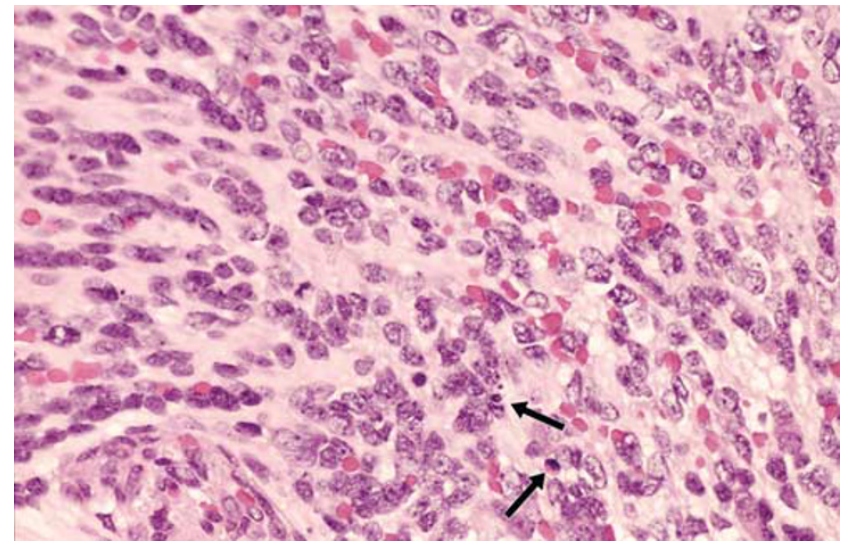

Figure 6 Immature neuroepithelium in an ovarian immature teratoma, showing slightly vesicular chromatin with occasional apoptotic bodies (arrows). testicular teratoma is less clear, ${ }^{60}$ since, as discussed, these tumors are malignant in the absence of overgrowth of immature neuroepithelium. Nonetheless, since such elements seem to be chemoresistant, their overgrowth probably does have an ultimately negative prognostic impact. (It is well established that the identification of PNET in postchemotherapy resections of patients with testicular germ cell tumors does have a seriously negative prognostic significance. ${ }^{60}$ ) Overgrowth of other types of neural elements has also been described in ovarian teratomas, resulting in different forms of 'monodermal' neuroectodermal tumors, including ovarian ependymoma (differentiated neuroectodermal tumor) (Figure 8) and glioblastoma (anaplastic neuroectodermal tumor). ${ }^{58}$ Ovarian ependymomas have a low-grade malignant course, and ovarian glioblastoma, like PNET, pursues an aggressive

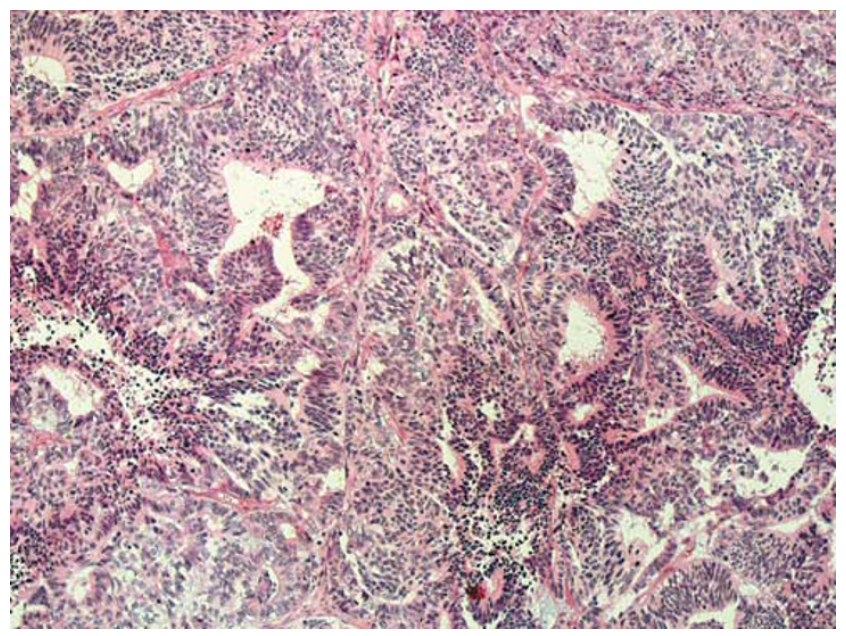

Figure 7 Primitive neuroectodermal tumor, consisting of a large, confluent aggregate of immature neuroepithelium that forms tubules lined by stratified cells.

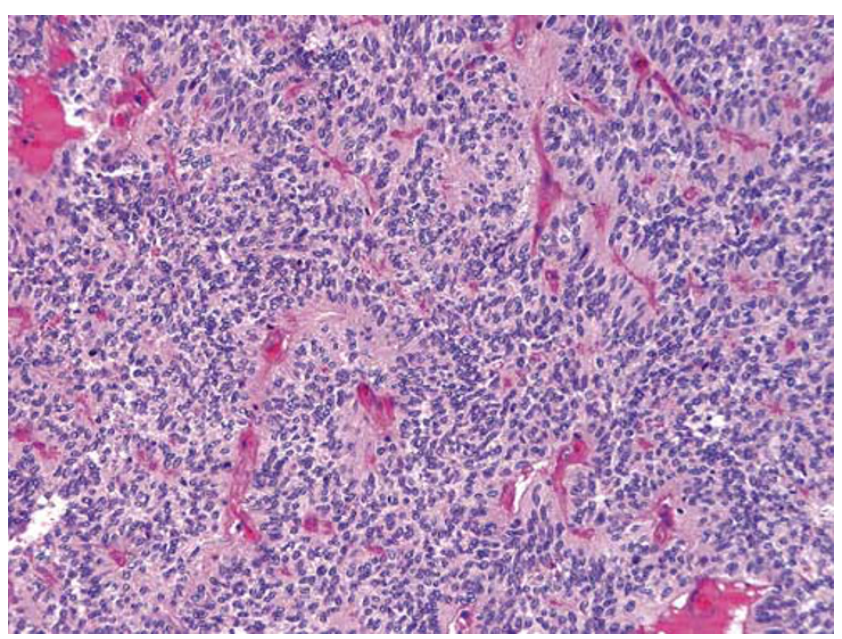

Figure 8 Ovarian ependymoma, showing perivascular pseudorosettes. 
course. ${ }^{58}$ Overgrowth of immature tubules, blastema, and stroma may result in nephroblastoma-like tumors. These are uncommon and seen most frequently in the postchemotherapy setting of patients with metastatic testicular germ cell tumors. ${ }^{61}$ Although experience is limited, they do not appear to have the same ominous prognostic significance in this setting as do PNETs.

The most common monodermal teratoma is struma ovarii, but, enigmatically, struma testis is so rare that no appreciable experience exists to merit comment. Struma ovarii may be either solid or cystic, with the solid examples usually being glistening, tan-brown, or beefy red nodules. While the diagnosis of struma ovarii is usually straightforward, certain variants may pose diagnostic difficulties. $^{62}$ Cellular examples may lack conspicuous follicles and have a solid appearance or grow as hollow to solid tubules of clear cells that mimic metastatic renal clear cell carcinoma, primary clear cell carcinoma of mullerian-type, or Sertoli cell tumor (Figure 9). Tumors with oxyphilic cells may simulate steroid cell tumor or diverse other oxyphilic neoplasms. The key to the correct interpretation is extensive sampling to detect characteristic foci of follicles with intraluminal colloid. Appropriate immunostains, including thyroid transcription factor-1 and thyroglobulin, can also be used. Cystic examples of struma ovarii may have extensive areas of nondescript pale cuboidal epithelium lining cystic spaces, sometimes with small papillae having hyalinized fibrous cores. ${ }^{63}$ These are prone to misinterpretation as cystadenomas of surface epithelial origin, usually serous cystadenoma. In some cases of cystic struma, the follicles lack colloid and are lined by cells with pale cytoplasm, causing possible confusion with mucinous cystadenoma. A frequently helpful feature is the brown to green color of the cystic tumor, and extensive sampling will often identify well-formed, though dispersed,

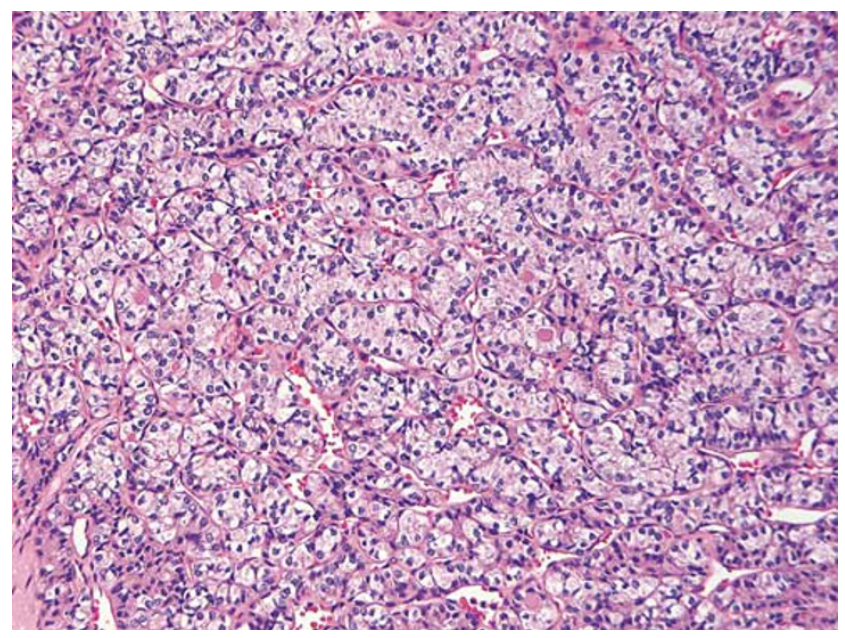

Figure 9 Struma ovarii with solid tubules and clear cells simulating Sertoli cell tumor. Note focal colloid. thyroid follicles in the fibrous septa between cysts. ${ }^{63}$ The cellular examples just noted should not be misinterpreted as follicular carcinoma, which is rare in struma ovarii and requires the identification of clear-cut invasive growth (capsular penetration) or vascular invasion. When 'malignant struma' does occur, it is almost always in the form of papillary carcinoma, with the same histologic features as in the thyroid gland and an excellent prognosis ${ }^{64}$ As in the thyroid gland, degenerative-based pseudopapillae on the background of adenomatous changes should be distinguished from papillary carcinoma using conventional thyroid criteria.

Another relatively common monodermal teratoma is gonadal carcinoid tumor. These lesions are generally similar in the ovary and testis (except for the restriction to date of strumal carcinoid to the ovary), typically have a solid, tan to yellow gross appearance, and usually show an insular or 'mid-gut' type of pattern and less commonly trabecular growth. ${ }^{65-68}$ In many cases, there is retraction artifact between the islands of carcinoid tumor and the surrounding fibrous stroma. They may be admixed with other teratomatous elements, but do not occur with nonteratomatous germ cell tumor components in the testis and rarely do in the ovary. This observation, plus the absence of IGCNU in the testicular cases ${ }^{26,66}$ suggest that the testicular carcinoids have a pathogenesis similar to ovarian or prepubertal testicular teratoma. Gonadal carcinoids usually pursue a clinically benign course. They must be distinguished from gonadal metastasis of carcinoid tumor, with prominent lymphovascular invasion and bilateral involvement favoring metastasis and associated teratomatous elements indicating a primary lesion. ${ }^{65,69}$ Strumal carcinoid is a unique tumor with thyroid follicles admixed with carcinoid..$^{70}$ Like ovarian carcinoid, it rarely metastasizes.

Mucinous carcinoid is the rarest form of primary gonadal carcinoid and, thus far, only documented in the ovary. ${ }^{71}$ It shows a spectrum of appearances, from well-differentiated examples consisting of glands lined by goblet and neuroendocrine cells, lacking atypia and 'floating' within mucin pools, to atypical examples having cribriform and fused glands lined by stratified cells with mucinous and neuroendocrine features, to those with a frankly carcinomatous component. Many cases are associated with either a teratomatous or mucinous tumor of surface epithelial type. As with the distinction of primary from metastatic carcinoid tumor of any type in the gonads, the presence of those associated elements may be important in distinguishing a primary mucinous carcinoid of the ovary from a metastasis of appendiceal origin.

\section{Gonadal teratomas-summary}

In summary, there are benign gonadal teratomas that are derived from nontransformed germ cells; these 
include the usual mature ovarian teratoma, prepubertal testicular teratoma, and dermoid and epidermoid cysts of the testis. There are malignant gonadal teratomas that are malignant because of their derivation from a malignant germ cell through the intermediary forms of an invasive germ cell tumor, such as yolk sac tumor or embryonal carcinoma ('preteratomatous' malignant transformation). This applies to most postpubertal testicular teratomas (with the exceptions of dermoid and epidermoid cyst and possibly carcinoid tumor), and it seems likely also to explain the rare teratomatous elements that develop in the uncommon mixed germ cell tumors of the ovary. Additionally, some gonadal teratomas are malignant because of 'post-teratomatous' malignant transformation; such tumors usually occur in the ovary and exhibit a spectrum of biologic behavior, with low-grade examples including grades 1 and 2 immature teratoma, differentiated neuroectodermal tumors (eg, ependymoma), malignant struma (papillary carcinoma in struma ovarii), carcinoid and strumal carcinoid. High-grade examples include dermoid cysts with squamous cell carcinoma or various sarcomas or melanoma, primitive neuroectodermal tumor, and ovarian glioblastoma.

\section{Germinoma}

Seminoma is the most common testicular germ cell tumor, representing $50 \%$ of the cases, ${ }^{3,4,26}$ and dysgerminoma the second most common ovarian germ cell tumor, although it represents only about $2 \%$ of them because of the marked predominance of teratomas in the ovary compared to their much lesser frequency in the testis (Table 1). ${ }^{6}$ This tumor is essentially morphologically identical in the two gonads, and so this discussion considers some of the diagnostic problems posed by seminoma and dysgerminoma together.

The classic pattern of germinoma is distinctive and readily recognized based on its overall sheetlike arrangement of clear cells with well-defined cytoplasmic borders (in well-fixed specimens) and flattened, 'squared-off' nuclear membranes that is subdivided into variably sized, smaller groups of cells (alveolar aggregates, nests, clusters) by lymphocyte-bearing, fibrovascular septa. There are, however, some unusual patterns that are prone to misinterpretation. Occasional germinomas have a microcystic or cribriform arrangement that may suggest yolk sac tumor (Figure 10). ${ }^{26,72}$ In our experience, this finding is more common in seminoma than dysgerminoma. This change may, in part, be secondary to edema because some examples of this phenomenon have faintly eosinophilic fluid within the cystic spaces, but in other examples this feature is lacking. Some cases have few lymphocytes, further complicating the interpretation since a lymphocytic infiltrate is a usual feature of typical

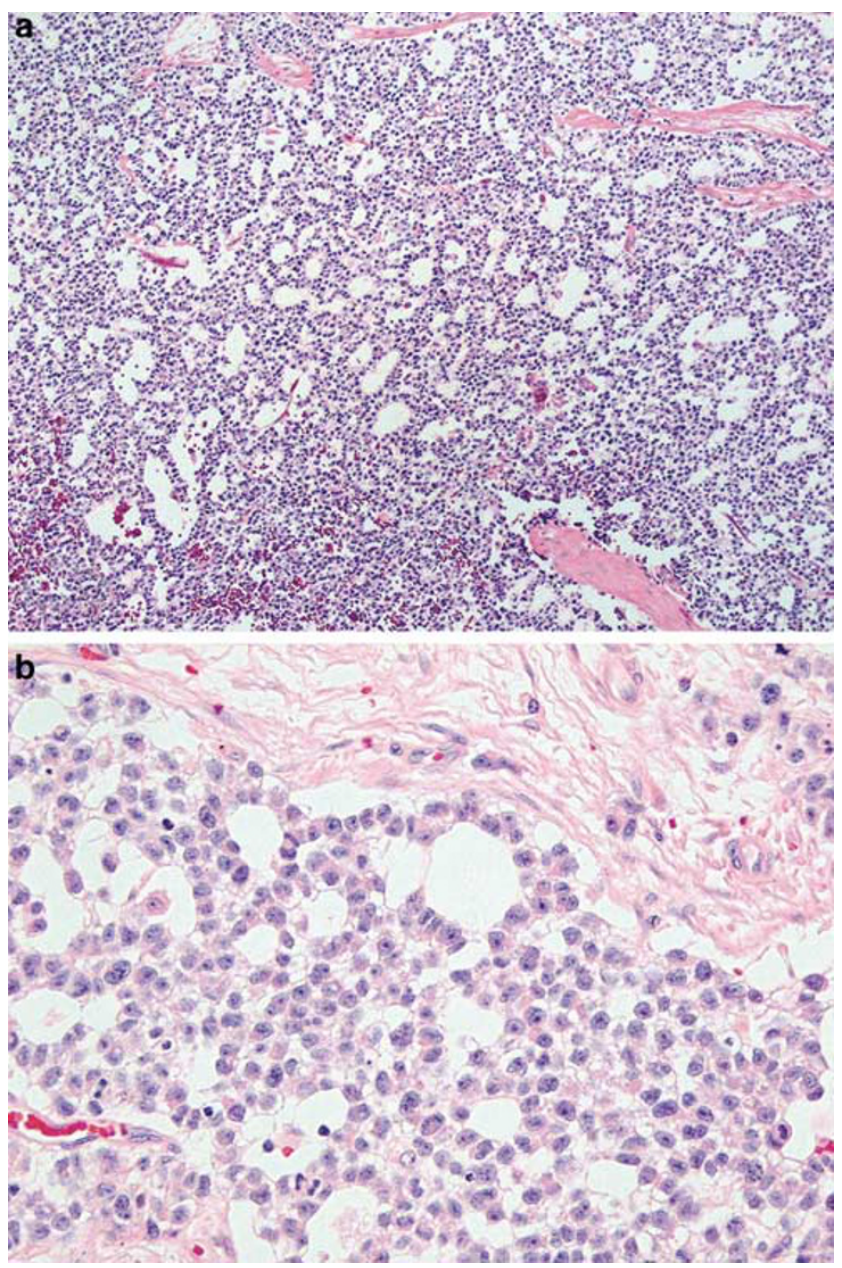

Figure 10 (a) Microcystic seminoma simulating yolk sac tumor. The cysts are lined by polygonal tumor cells and many contain exfoliated cells. Note absence of lymphocytes. (b) Higher magnification shows typical cytological features of seminoma.

germinoma, occurring in almost all of them, ${ }^{73}$ and its presence is a helpful criterion for the diagnosis of germinoma, whereas yolk sac tumor generally lacks lymphocytes. Helpful differential features include that the cystic spaces in these unusual cases of germinoma frequently contain exfoliated tumor cells or inflammatory cells and are lined by polygonal tumor cells rather than the flattened lining cells with compressed nuclei of microcystic yolk sac tumor (Figure 10a). The key differential findings, however, are retention of the usual cytological features of germinoma cells (Figure 10b) and absence of other patterns that would be expected in yolk sac tumor. Immunostains for cytokeratin (AE1/AE3), alpha-fetoprotein (AFP), and OCT3/4 ${ }^{74}$ are helpful, typically staining negatively (AE1/AE3 and AFP) and positively (OCT3/4) in germinoma and showing opposite reactivities in yolk sac tumor (Figure 11) (Table 2). OCT3/4 (also known as POU5F1) is a newly described nuclear transcription factor that is expressed in human embryonic and 

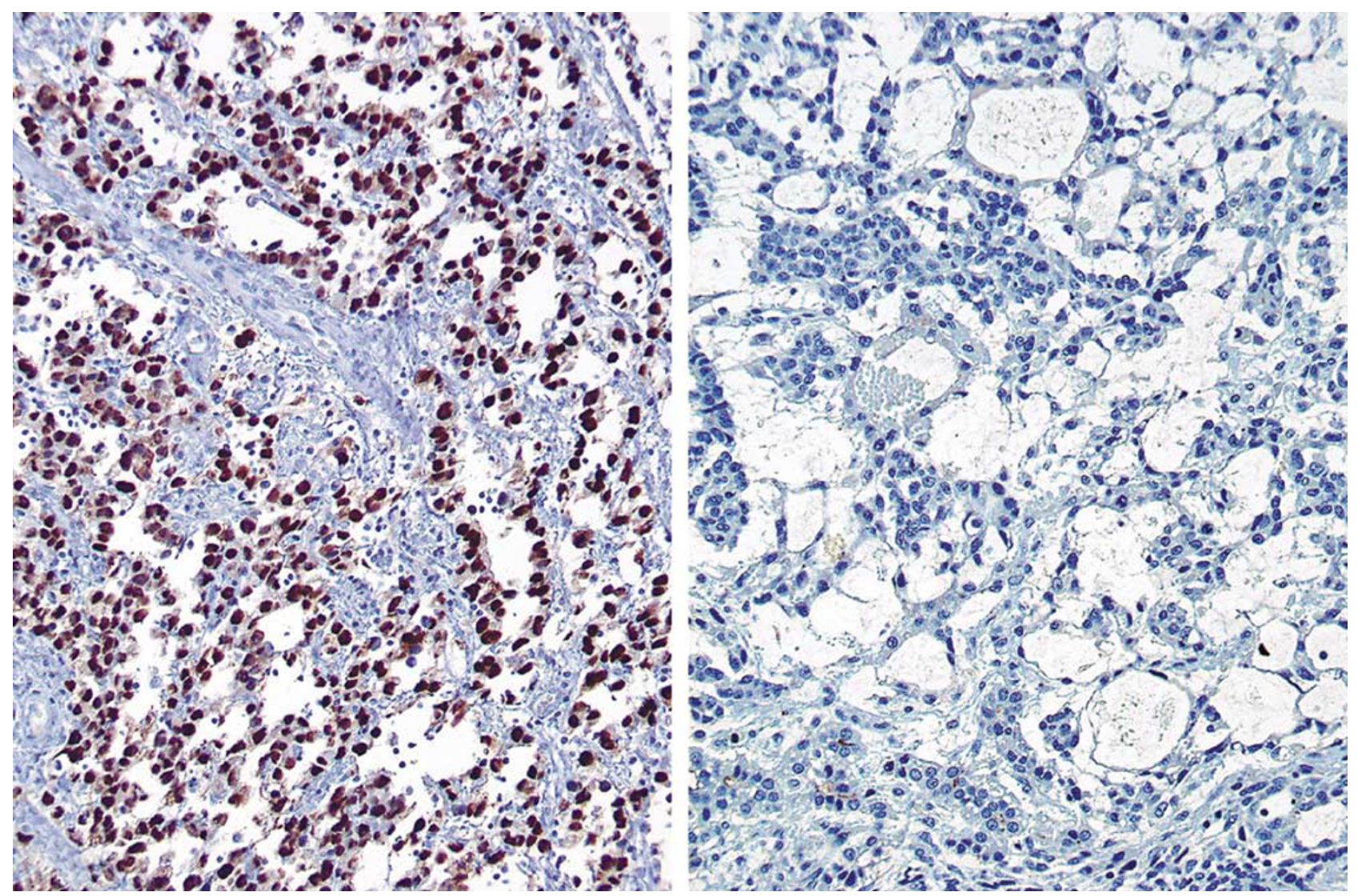

Figure 11 Positive nuclear staining with OCT3/4 in a microcystic seminoma (left) compared to a negative reaction in a microcystic yolk sac tumor (right).

stem cells and has been found to mark the nuclei of germinomas and embryonal carcinomas with very high sensitivity and specificity, being positive in all 189 examples of these tumors in two studies and reactive in no other form of invasive germ cell tumor or other form of primary testicular tumor. ${ }^{7,75}$ Additionally, among 3439 tumors studied with tissue microarrays, apart from germinoma, embryonal carcinoma, and gonadoblastoma, only three other tumors stained positively (one of 50 clear cell carcinomas of the kidney, one of 50 squamous cell carcinomas of the lung and one of 47 large cell carcinomas of the lung). ${ }^{74}$

Occasional germinomas have a solid tubular pattern characterized by elongated nests with a somewhat palisaded arrangement of tumor cells at their periphery (Figure 12). ${ }^{76,77}$ This may cause confusion with Sertoli cell tumor, but adjacent intratubular germ cell neoplasia of the unclassified type (IGCNU) may be helpful, if present, and more reliably the nuclei have the typical appearance of germinoma nuclei. When the light microscopic features are ambiguous, immunostains for placental alkaline phosphatase and OCT3/4 (positive in germinoma and negative in Sertoli cell tumor) and inhibin (negative in germinoma and often positive in Sertoli cell tumor) ${ }^{78-80}$ are helpful (Table 2).
Focal intertubular growth is common in seminoma, and rarely characterizes most of, or the entire, tumor. ${ }^{81}$ Seminomas with purely intertubular growth may not produce a clinical mass, and the tumor is often heralded by metastases or found during the investigation of infertility. ${ }^{81}$ The neoplastic infiltrate in these cases may be deceptively subtle and potentially overlooked at scanning magnification. The seminiferous tubules remain intact with, in some cases, expansion of the space between them if the tumor cells are sufficiently numerous. In some cases, however, the seminoma cells subtly infiltrate the interstitium as individual cells or small clusters without appreciable intertubular expansion (Figure 13). They may be admixed with clusters of Leydig cells, which may further mask their presence. Clues to this process include the common associated lymphocytic infiltrate in the interstitium (although this may be misinterpreted as a manifestation of viral orchitis), the usual presence of IGCNU and the frequently associated testicular atrophy and Leydig cell hyperplasia. ${ }^{81}$ Because lymphomas and metastases may show prominent intertubular growth, it is important to identify the cytological features of seminoma cells in these cases to rule out other neoplastic infiltrates. Appropriate immunostains can easily resolve the differential if necessary. 
Table 2 Usual immunostaining results for selected gonadal tumors and certain differential considerations

\begin{tabular}{|c|c|c|c|c|c|c|c|c|c|}
\hline Immunostain & $\begin{array}{l}\text { Germi- } \\
\text { noma }\end{array}$ & $\begin{array}{l}\text { Spermato- } \\
\text { cytic } \\
\text { seminoma }\end{array}$ & $\begin{array}{l}\text { Embryonal } \\
\text { carcinoma }\end{array}$ & $\begin{array}{l}\text { Yolk } \\
\text { sac } \\
\text { tumor }\end{array}$ & $\begin{array}{l}\text { Sertoli } \\
\text { cell } \\
\text { tumor }\end{array}$ & $\begin{array}{l}\text { Adenoma- } \\
\text { toid } \\
\text { tumor }\end{array}$ & $\begin{array}{c}\text { Large } \\
\text { cell car- } \\
\text { cinoma }\end{array}$ & $\begin{array}{l}\text { Glandular } \\
\text { yolk sac } \\
\text { tumor }\end{array}$ & $\begin{array}{c}\text { Endo- } \\
\text { metrioid } \\
\text { carcinoma }\end{array}$ \\
\hline Alpha-fetoprotein & - & - & \pm & + & - & - & - & + & - \\
\hline Cytokeratin (AE1/AE3) & \pm & - & ++ & ++ & \pm & ++ & ++ & ++ & ++ \\
\hline Cytokeratin 7 & \pm & ? & + & - & \pm & + & + & - & + \\
\hline $\begin{array}{l}\text { Epithelial } \\
\text { membrane antigen }\end{array}$ & - & - & - & - & \pm & + & + & - & + \\
\hline ОСТ3/4 & + & - & + & - & - & - & - & - & - \\
\hline $\begin{array}{l}\text { Placental alkaline } \\
\text { phosphatase }\end{array}$ & ++ & \pm & + & \pm & - & - & \pm & \pm & \pm \\
\hline CD 30 & - & - & + & \pm & ? & ? & \pm & ? & ? \\
\hline Inhibin & - & - & - & - & + & - & - & - & - \\
\hline C-kit & ++ & \pm & \pm & \pm & ? & ? & \pm & \pm & + \\
\hline Calretinin & - & $?$ & - & - & \pm & \pm & \pm & $?$ & \pm \\
\hline
\end{tabular}

+ or ++ indicates most cases are positive or strongly positive; \pm indicates variable staining; - indicates most cases are negative; ? indicates few data are available.

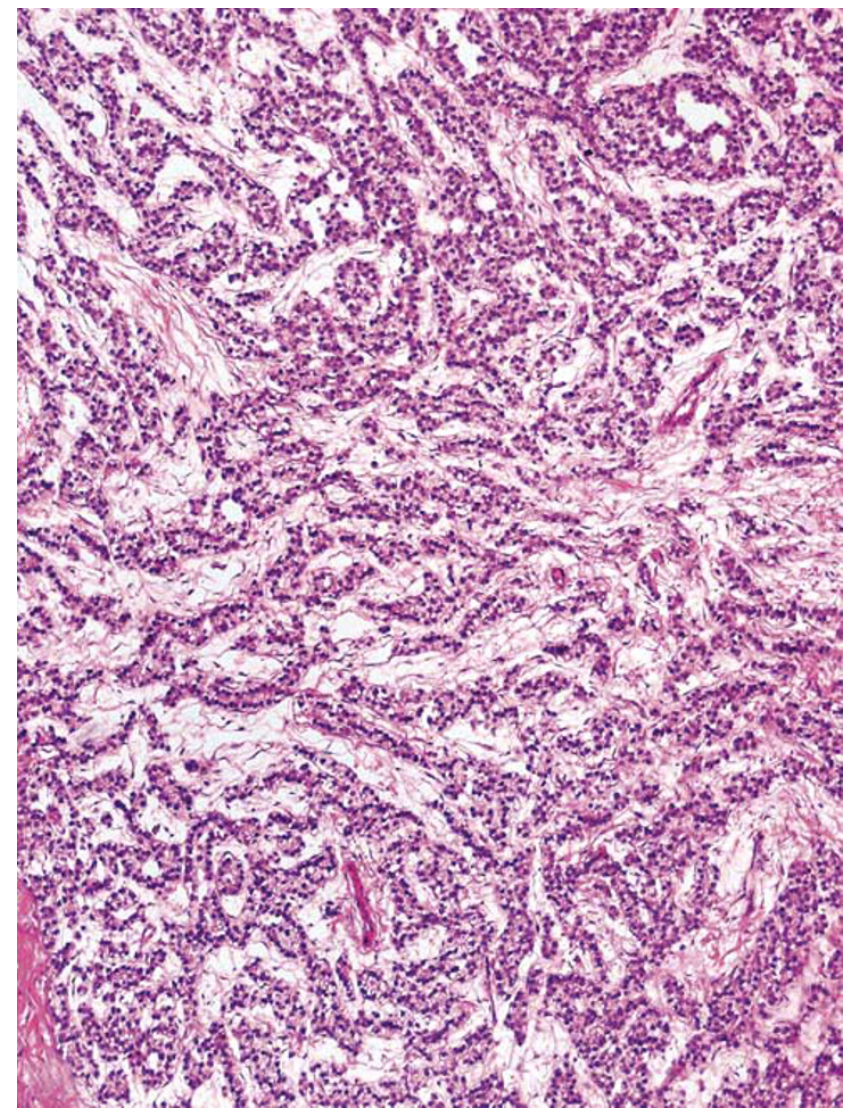

Figure 12 Tubular pattern in a seminoma, with mostly solid tubule-like structures.

Germinomas may have areas with cells that have denser, sometimes eosinophilic or amphophilic cytoplasm and increased nuclear crowding and irregularity; this appearance must be distinguished from embryonal carcinoma. Frequently, these findings relate to suboptimal fixation of germinoma, resulting in poorly defined cell membranes, cyto-

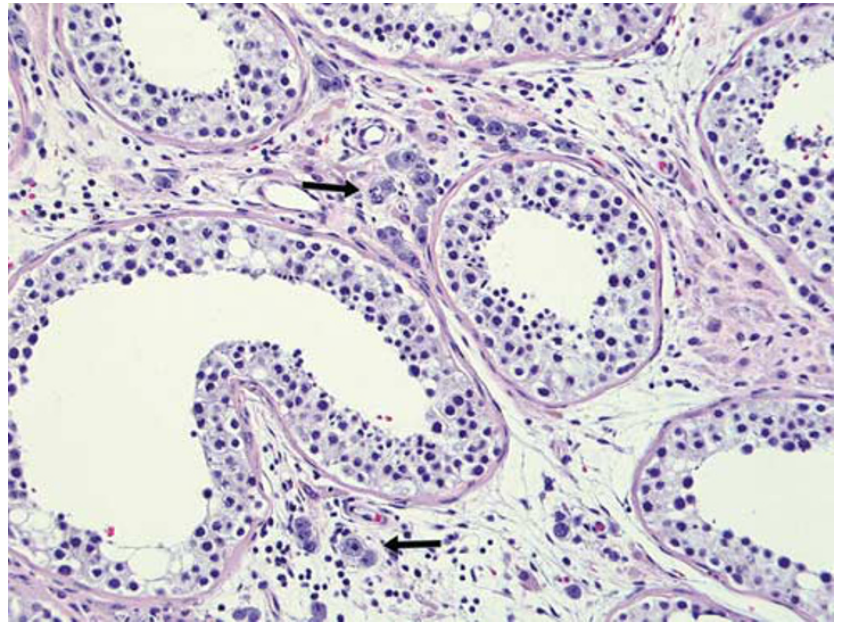

Figure 13 Intertubular pattern seminoma (arrows).

plasmic autolysis and secondary nuclear crowding, but occasionally they occur as real phenomenon in well-processed material. Some germinomas may have these features diffusely, yielding an overall plasmacytoid appearance (Figure 14). In the past, many such testicular cases were considered 'anaplastic' seminomas, a term that often causes confusion in the minds of pathologists and oncologists alike and which is not recommended. Tickoo et a ${ }^{82}$ identified a number of seminomas that had these histological features and that also tended to stain more prominently for cytokeratin and CD30 than the usual seminoma. They found that these 'atypical' seminomas tended to present at a higher tumor stage and advocated that they may merit more aggressive treatment. Others, myself included, however continue to place these cases into the seminoma category without separately designating them as atypical since it is not clear that different treatment is indicated. On most occasions the diagnosis of embryonal carcinoma is straightforward, but small 


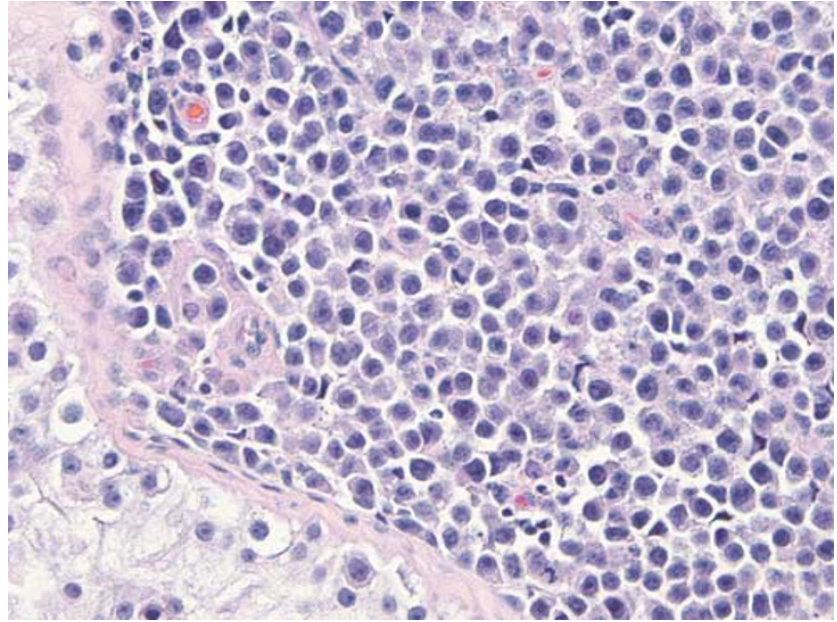

Figure 14 Seminoma with plasmacytoid appearance.

foci within a background of germinoma may be challenging to identify. Any distinct epithelial differentiation, gland or papilla formation, should be regarded as evidence of embryonal carcinoma. In the absence of distinct epithelial features, a combination of findings (nuclear pleomorphism, nuclear crowding and irregularity, dense cytoplasm, indistinct cell borders) will cause concern for transformation of germinoma to embryonal carcinoma. For those borderline cases where there is ambiguity at the routine light microscopic level, immunostains for CD30 and cytokeratin (AE1/AE3) may be useful. ${ }^{82}$ Positivity in the problematic areas for these markers that contrasts with negativity in the typical germinoma areas provides support for an embryonal carcinoma component (Table 2). If the borderline findings are diffuse, impressive AE1/AE3 and CD30 reactivity should be required, rather than focally prominent positivity for one of these markers, before accepting the tumor as embryonal carcinoma.

About $5 \%$ of germinomas have distinct admixed syncytiotrophoblast cells, ${ }^{73,83}$ although additional cases with inconspicuous syncytiotrophoblast cells can be identified using immunohistochemical stains for human chorionic gonadotropin (hCG) ${ }^{84}$ When these cells are widely dispersed, as is typically the case, this phenomenon does not usually create diagnostic confusion. However, when they occur in sizable clusters, there may be concern for choriocarcinoma (Figure 15). Unlike choriocarcinoma, however, these tumors lack the plexiform admixture with cytotrophoblast cells, which show a greater degree of pleomorphism than the uniform, germinoma cells associated with admixed syncytiotrophoblast cells. Additionally, other areas of the tumor have the typical findings of germinoma. Syncytiotrophoblast cells in germinoma, just as in choriocarcinoma and other types of germ cell tumor, synthesize and secrete hCG, which may, therefore, cause a number of hormonal manifestations. ${ }^{85}$ These

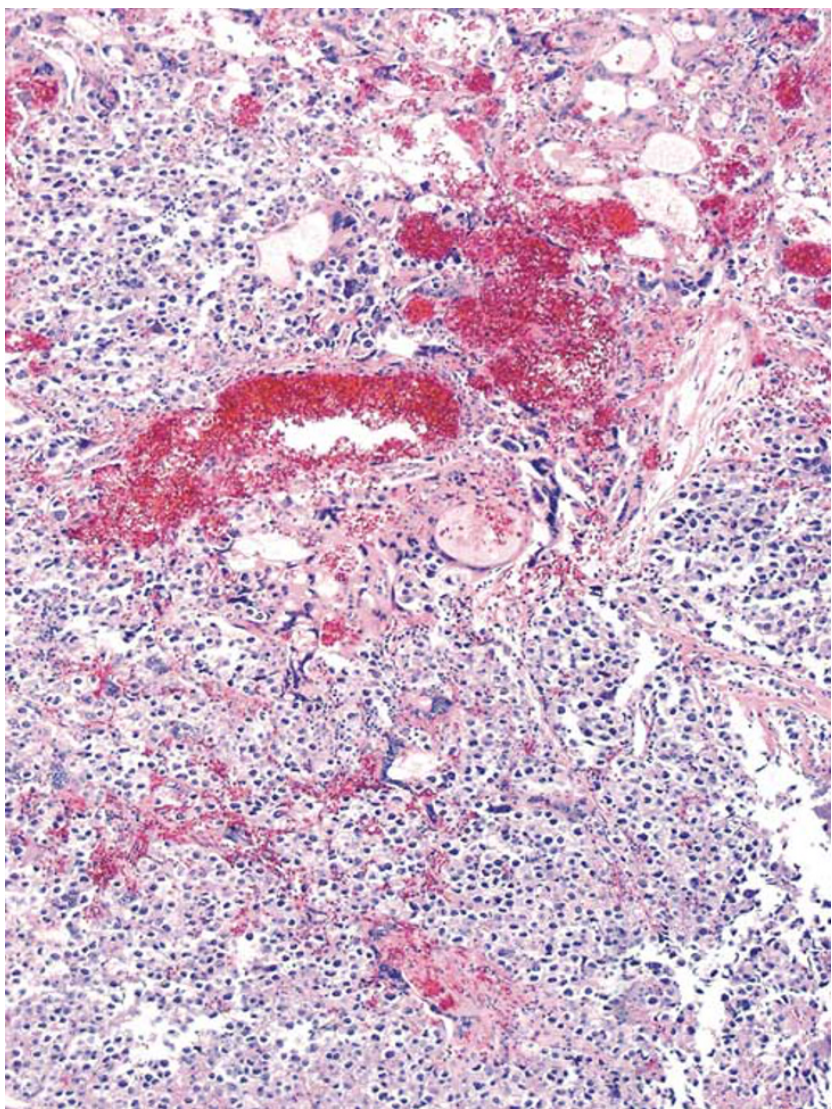

Figure 15 Seminoma with prominent syncytiotrophoblast cells and associated blood lakes.

include androgenic ones from secondary hyperplasia of Leydig cells in the testis or stimulation of the ovarian stroma; estrogenic ones, either because of direct stimulation of ovarian stroma and/or nonneoplastic follicles or peripheral conversion of androgen to estrogen, thereby resulting in abnormal uterine bleeding or, in men, gynecomastia; and hyperthyroidism because of the thyroid-stimulating hormone-like activity of hCG. ${ }^{86,87}$ A number of other interesting, paraneoplastic manifestations may be seen in association with germ cell tumors, especially germinomas, including hypercalcemia, ${ }^{86,88}$ hypoglycemia, ${ }^{89}$ exophthalmos, ${ }^{90,91}$ autoimmune hemolytic anemia (usually ovarian dermoids), ataxia telangiectasia, ${ }^{86}$ and limbic encephalopathy. ${ }^{92,93}$

\section{Spermatocytic seminoma}

Spermatocytic seminoma may be confused with usual seminoma, a very important distinction from the clinical standpoint since spermatocytic seminomas virtually never metastasize (except for those with a rare complication mentioned below) and do not merit treatment apart from orchiectomy. ${ }^{94-97}$ This tumor is limited to the male gonad and has a number of fascinating aspects. Although most 
patients with spermatocytic seminoma are older (mean, 55 years) ${ }^{98}$ than those with usual seminoma (mean, 40 years), ${ }^{4}$ there is considerable overlap. Grossly, spermatocytic seminoma often has a more gelatinous quality than the typically uniformly fleshy nature of usual seminoma. The sheet-like arrangement of spermatocytic seminoma may provoke an initial impression of usual seminoma, but closer inspection shows a paucity of lymphocytes, round rather than 'squared off' nuclei and variable cell size ('tripartite' cell population having small, 'lymphocyte-like' tumor cells, intermediate sized cells, and large cells that are sometimes multinucleated). In the 'anaplastic' variant of spermatocytic seminoma, ${ }^{99}$ named for its uniformly atypical cells with nucleolar prominence (Figure 16) (although lacking clinical evidence of aggressive behavior), the relatively monomorphous tumor cell population may prompt consideration of the solid pattern of embryonal carcinoma. Most such cases, however, have a typical appearance elsewhere, and it is preferable to regard this appearance as part of the spectrum of spermatocytic seminoma rather than cause clinical concern by use of the term 'anaplastic'. Unlike usual seminoma or embryonal carcinoma, spermatocytic seminoma lacks IGCNU, ${ }^{100}$ a feature which is helpful in its diagnosis. Additionally, immunostains for placental alkaline phosphatase and OCT3/4 are positive in both usual seminoma and embryonal carcinoma but essentially negative (placental alkaline phosphatase) to always negative (OCT3/4) in spermatocytic seminoma, ${ }^{74,101,102}$ which also shows negativity for CD30 ${ }^{103}$ (positive in embryonal carcinoma) and AE1/AE3 cytokeratin ${ }^{102}$ (positive in embryonal carcinoma) (Table 2). The presence of polyploid populations of tumor cells in spermatocytic seminoma $^{104}$ leads to the speculation that spermatocytic seminoma results from self-fertilization of germ cells, a hypothesis that is also consistent with its exclusively testicular occurrence.

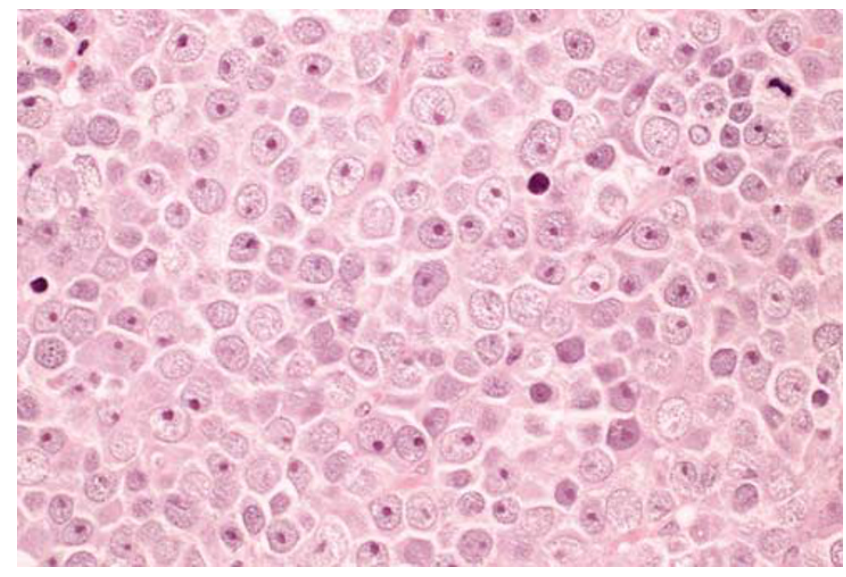

Figure 16 'Anaplastic' spermatocytic seminoma with a monomorphic population of tumor cells with prominent nucleoli.
On rare occasions, sarcomas, usually rhabdomyosarcoma or undifferentiated, high-grade sarcoma, may develop in spermatocytic seminomas, typically presenting as rapidly growing testicular masses in patients with previously relatively stable lesions of long duration. ${ }^{104-106}$ Unlike the situation with uncomplicated spermatocytic seminomas, those with sarcomatous change develop metastases in a hematogenous distribution in many of the cases.

\section{Embryonal carcinoma}

Embryonal carcinoma is relatively common among testicular germ cell tumors, where $10 \%$ are pure embryonal carcinomas and even more have it as a component of a mixed germ cell tumor (Table 1). Yet, for unknown reasons, embryonal carcinoma is rare among ovarian germ cell tumors ${ }^{107}$ (Table 1). The sheets, glands, and papillary structures composed of primitive epithelial cells with crowded, pleomorphic nuclei are usually distinctive among the germ cell tumors and pose no diagnostic problem in the gonad except for their distinction from uncommon atypical seminomas, as already discussed. When patients, however, present with metastatic lesions without a known gonadal primary, the distinction from an undifferentiated large cell carcinoma can be problematic. The typically younger age of the patient, however, is helpful, and a panel of immunostains that includes CD30, EMA, and OCT3/4 can confirm the diagnosis in this situation (Table 2).

\section{Yolk sac tumor}

This is the third most common form of ovarian germ cell tumor $(\sim 1 \% \text { of cases })^{6}$ and is a common component of mixed germ cell tumors of the testis (Table 1). Most of the ovarian yolk sac tumors occur as pure neoplasms, whereas pure yolk sac tumors of the testis are rare in adults but the most common testicular germ cell tumor in children, peaking at 1.5 years of age and representing about $70 \%$ of pediatric testicular germ cell tumors. ${ }^{108}$ There are numerous patterns of yolk sac tumor, beautifully described and illustrated by Teilum ${ }^{109-112}$ in his classical writings on this tumor, and only a few of the more challenging ones will be discussed here, some of them recognized since Dr Teilum's death. Often these are admixed with other patterns that facilitate the diagnosis.

One of the classic errors in tumor pathology is the misinterpretation of clear cell carcinoma of the ovary as yolk sac tumor. For years both these tumors were considered the same entity until Teilum resolved that issue. Clear cell carcinoma shares with yolk sac tumor tubular, cystic, and papillary patterns, but other distinctive yolk sac tumor patterns are absent; the patients are significantly older than those with yolk sac tumor, and it is not associated 
with elevated serum alpha-fetoprotein, although, treacherously, it can stain for it immunohistochemically. ${ }^{113}$ Only uncommon or deceptive patterns are considered here.

The solid pattern of yolk sac tumor mimics germinoma by virtue of its sheet-like arrangement of lightly staining cells with well-defined borders (Figure 17). A greater degree of nuclear variability, occasional suggestion of microcysts (although, as mentioned, this feature may also be seen less commonly in germinomas) and scarcity of lymphocytes in solid yolk sac tumor are helpful in making the distinction from germinoma, ${ }^{114}$ as is the occasional occurrence of intracytoplasmic hyaline globules and extracellular basement membrane deposits, features lacking in germinomas. ${ }^{115}$ Most helpful is the occurrence of more distinctive yolk sac tumor patterns, which are almost always present in sizable samples but may be absent in limited material, as in biopsies from metastatic sites. Immunostains can assist in problematic cases since cytokeratin (AE1/AE3) and AFP stains (Figure 17b) are often

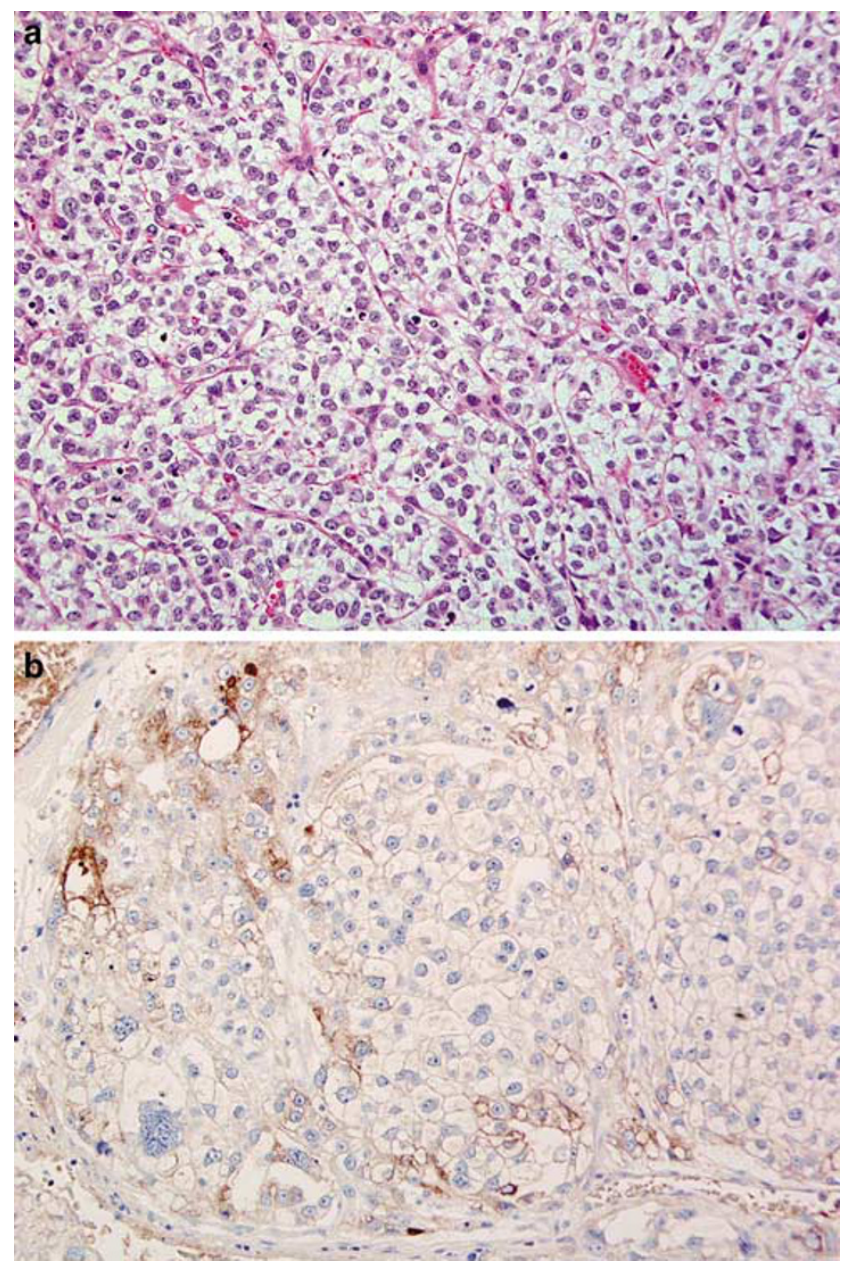

Figure 17 (a) Solid pattern yolk sac tumor resembling germinoma. (b) Alpha-fetoprotein immunostain in a similar case. positive in solid yolk sac tumor and negative in germinoma. ${ }^{114}$ Additionally, the OCT3/4 immunostain is positive in germinoma, but negative in yolk sac tumor (Table 2). ${ }^{74}$ Rarely there is a solid, blastema-like growth of small cells in yolk sac tumor, but this is always associated with typical patterns in our experience.

Glandular patterns occur in about one-third of yolk sac tumors, ${ }^{115}$ usually taking the form of scattered, simple glands and representing no diagnostic problem. Rarely, a predominantly or purely glandular pattern occurs in primary yolk sac tumors, almost always in the ovary (see below), often with prominent subnuclear vacuolization, thereby resembling secretory endometrioid carcinoma (endometrioid-like yolk sac tumor) (Figure 18). ${ }^{116}$ In cases of testicular germ cell tumor, purely glandular patterns are almost exclusively seen in metastases resected after chemotherapy rather than in the primary tumors. They are most common in recurrences seen two or more years after the initial diagnosis. ${ }^{117}$ Endometrioid-like yolk sac tumor occurs in younger patients (mean, 22 years) ${ }^{116}$ than those with endometrioid adenocarcinoma (mean, 56 years) and the latter is frequently associated with endometriosis or an endometrioid adenofibroma. ${ }^{6}$ The frequently elevated serum AFP level in patients with glandular yolk sac tumors ${ }^{116}$ contrasts with the normal level in cases of endometrioid adenocarcinomas. This differential is complicated by the fact that rarely yolk sac tumor arises on the background of a somatic ovarian neoplasm, which is most commonly endometrioid adenocarcinoma, ${ }^{118}$ but these tumors occur in an older age group than yolk sac tumors and have a number of helpful pathological distinguishing features, most important of which is the associated conventional carcinoma. The differential of a purely glandular testicular yolk sac tumor is limited, mainly being with a rare adenocarcinoma

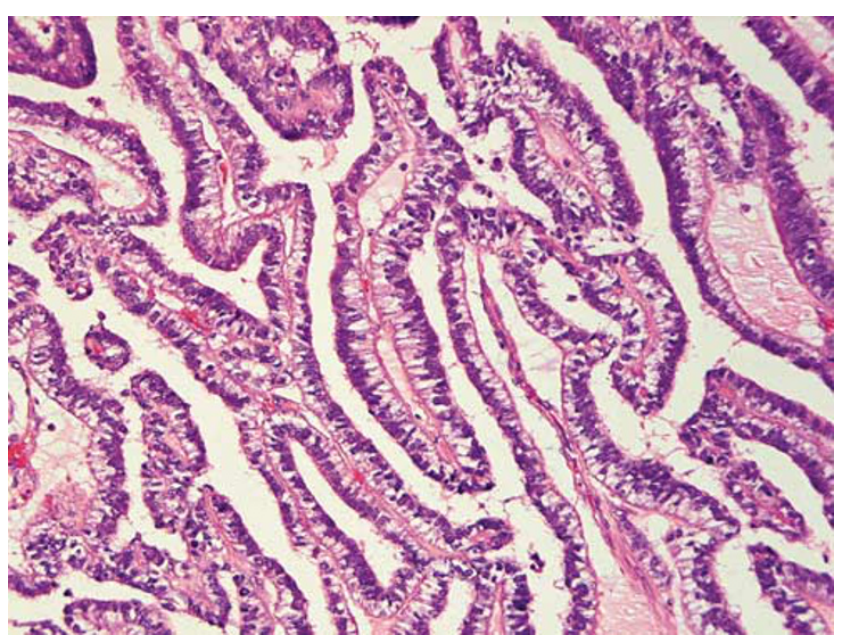

Figure 18 Glandular yolk sac tumor of the ovary, resembling endometrioid adenocarcinoma. 
that has developed from pre-existing teratoma. Immunostains are helpful in distinguishing adenocarcinoma and glandular yolk sac tumor; AFP is positive, and EMA and cytokeratin 7 are negative in endometrioid-like yolk sac tumor and show opposite reactivities in endometrioid adenocarcinoma (Table 2). ${ }^{119,120}$

Hepatoid differentiation, usually scattered, small clusters of polygonal cells with abundant eosinophilic cytoplasm and prominent nucleoli, is common in yolk sac tumors, occurring in $22 \%$ of cases in one series ${ }^{115}$ and is infrequently seen in other ovarian tumors. ${ }^{121}$ Rarely, there is a predominant or pure hepatoid pattern (Figure 19); ${ }^{122,123}$ in males prominent hepatoid differentiation is almost always seen in metastatic lesions resected after chemotherapy, particularly in the context of late recurrence, ${ }^{117}$ rather than in the primary. For pure or predominantly hepatoid ovarian yolk sac tumors, the differential includes the rare hepatoid carcinoma. ${ }^{124}$ The occurrence of the latter in older patients and its common admixture with an adenocarcinomatous component of surface epithelial type (usually serous), sometimes evident only in metastases, are helpful findings. Distinction of hepatoid yolk sac tumor from metastatic hepatocellular carcinoma to the ovary is usually facilitated by knowledge of tumor in the liver, a history of long-standing liver disease and presence in the ovarian tumor of minor foci of yolk sac neoplasia.

Lastly, yolk sac tumors commonly have abundant basement membrane deposits that surround individual and small groups of tumor cells. ${ }^{115}$ Rarely, this 'parietal' differentiation (named for the comparable structure in the rodent yolk sac) becomes predominant, leaving isolated tumor cells in a dense basement membrane matrix. This tends to occur most frequently, at least in testicular cancer patients, in resected metastases following chemotherapy, ${ }^{117,125}$ and it may be misinterpreted as a matrix-producing mesenchymal lesion if the pathologist is not aware of the phenomenon.

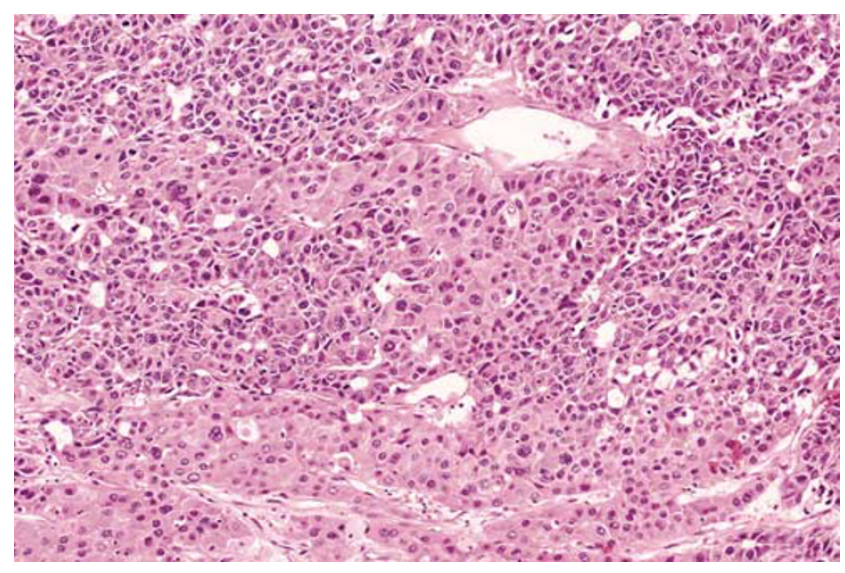

Figure 19 Hepatoid yolk sac tumor.

\section{Choriocarcinoma}

Choriocarcinoma is among the rarest of the gonadal germ cell tumors, with pure examples in either gonad representing well under $1 \%$ of the total number of germ cell tumors (Table 1). Because of its production of hCG, it may be associated with a number of hormonal manifestations mentioned already (see the section on Germinoma). Those in the testis are especially prone to present with metastases rather than a mass. The typical pattern is a plexiform arrangement of syncytiotrophoblast cells with mononucleated, mostly cytotrophoblast cells around foci of hemorrhage, although some examples may have a relatively inconspicuous syncytiotrophoblast component. Ovarian cases should be distinguished from metastatic gestational choriocarcinoma; a concomitant or proximate gestation almost always indicates the latter, whereas another germ cell tumor component indicates the primary nature of the ovarian tumor.

\section{Polyembryoma}

The polyembryoma is a distinctive form of mixed germ cell tumor of the gonads that is often separately categorized because of its unique histologic

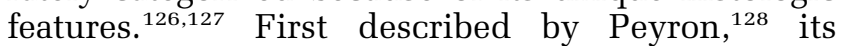
formation of embryo-like structures composed of primitive germ cell tumor components may be viewed conceptually as a bridge between the primitive and differentiated (teratoma) germ cell tumor types, leading some to place the polyembryoma into the category of the most immature of all teratomas. Indeed, perhaps every tumor of this type encountered to date has had at least a few differentiated teratomatous structures, such as glands, buttressing this viewpoint.

The tumor consists of small embryo-like bodies having a central 'germ disc' composed of embryonal carcinoma epithelium and two cavities, a dorsal one recapitulating the amniotic cavity and a ventral one recapitulating the yolk sac cavity (Figure 20). The latter is separated from the germ disc by a thin layer of yolk sac epithelium. The embryoid bodies lie in an edematous to myxoid stroma that has prominent blood vessels. They are usually somewhat evenly spaced and, as noted earlier, the intervening areas show minor degrees of glands or other more differentiated elements. Elements other than the embryoid bodies, however, should constitute less than $10 \%$ of the tumor for the 'polyembryoma' designation to be used. Hepatoid cells may rarely be seen, and syncytiotrophoblast giant cells are more frequent, sometimes causing endocrine manifestations. In some cases, the embryonal carcinoma and yolk sac epithelium proliferate to a limited degree and lose the orderly arrangement of the 'classic' embryoid body, with extension of these components beyond the confines of the embryoid body. The point at which one considers a small aggregate of 


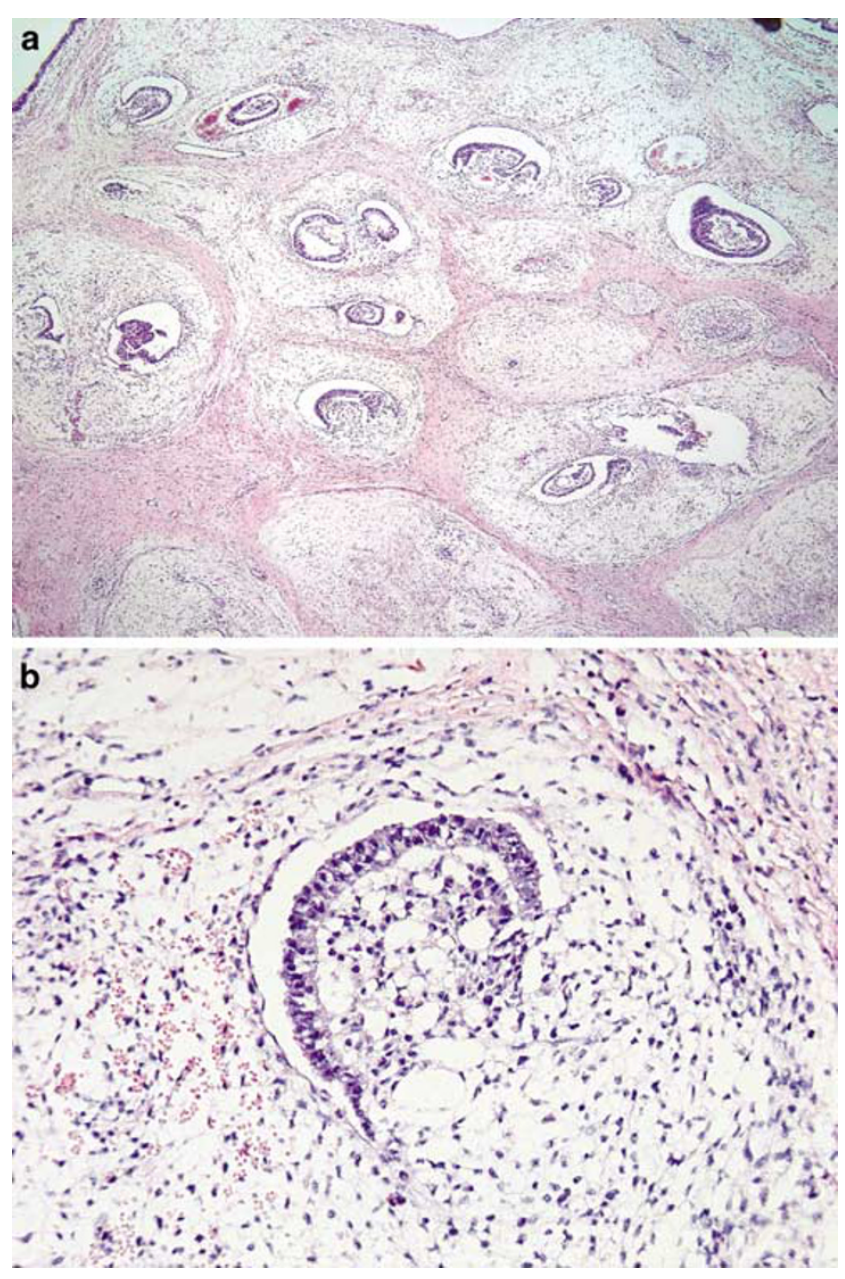

Figure 20 (a) Polyembryoma showing multiple embryoid bodies relatively evenly dispersed in a myxoid stroma. (b) Embryoid body having a core of embryonal carcinoma, a dorsal amniotic cavity, and a ventral component of yolk sac tumor.

cells a separate focus of embryonal carcinoma, or alternatively, yolk sac tumor is arbitrary, with one proposal being $3 \mathrm{~mm} .{ }^{129}$ Just as the presence of differentiated structures links the polyembryoma with the teratomas, so at the other end of the spectrum the phenomenon just referred to, which in daily practice we colloquially refer to as 'fragmentation of embryoid bodies', links them with the primitive germ cell tumors. Further example of this linkage is provided by the fact that if one looks carefully embryoid bodies are common in mixed germ cell tumors of the gonads and, simply because mixed germ cell tumors are more common in the testis and have more randomly arranged elements, embryoid bodies are typically a finding in testicular tumor pathology to a much greater degree than in the ovary. A further distinctive arrangement of yolk sac tumor and embryonal carcinoma epithelium is seen in the pattern that has been likened to a necklace and referred to as 'diffuse embryoma' (Figure 21). Like the polyembryoma, pure examples

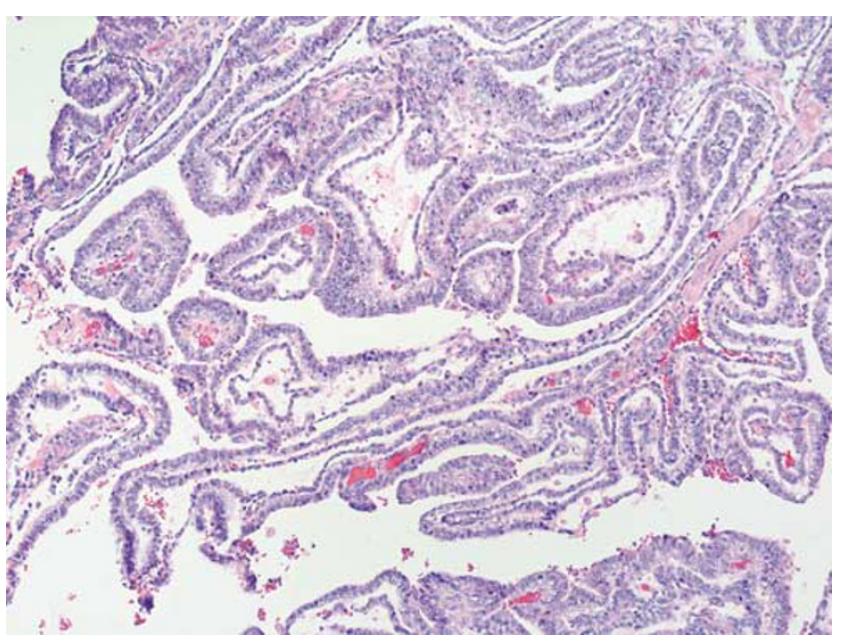

Figure 21 Diffuse embryoma showing the necklace-like arrangement of parallel ribbons of embryonal carcinoma and yolk sac tumor cells, the latter having a more flattened appearance.

of the diffuse embryoma are exceptionally rare, although this is a relatively frequent, focal pattern in mixed germ cell tumors of the testis.

\section{Mixed germ cell tumors}

Since, as mentioned in the introduction, one of the themes of this essay is contrasts between germ cell neoplasms in the two gonads, a few comments on mixed germ cell tumors are appropriate. Although their individual constituents are the same in the gonads, other striking differences exist, some already touched upon. First of all, they are much more common in the testis (33 vs $<1 \%$, Table 1). Almost any admixture is seen in the testis, many with roughly equal frequency, whereas in the ovary various combinations of yolk sac tumor, dysgerminoma, and teratoma account for the great majority. ${ }^{5}$ Finally, in the testis a random admixture of elements is typical, a more zonal distribution of two or more elements being more usual in the ovary, without implying that the opposite cannot be seen on occasion.

\section{Regression of primitive germ cell tumors}

Primitive germ cell tumors of the testis (but not those of the ovary) occasionally exhibit a remarkable phenomenon, spontaneous regression, the typical scenario being a patient who presents with metastatic disease with a clinically inapparent primary but who has at least 'ghost' evidence of pre-existing tumor on pathologic examination of the testis. In classic examples of this enigmatic phenomenon, there is no identifiable invasive neoplasm on microscopic examination but just dense, often hyaline scarring, sometimes with IGCNU in adjacent tubules. In an autopsy study, about $10 \%$ of patients 
S76

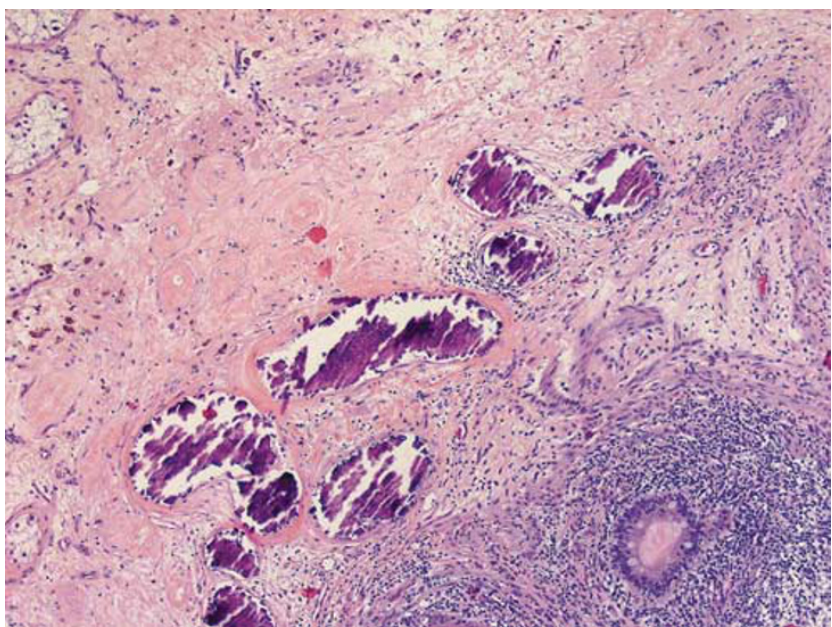

Figure 22 Regressed testicular germ cell tumor with area of scarring, coarse intratubular calcifications, lymphocytic infiltrates, and focal residual teratoma (bottom right).

who died of metastatic testicular germ cell tumors had such 'burnt-out' primary tumors. ${ }^{130}$ Features that are helpful in establishing a diagnosis of a regressed testicular germ cell tumor include, apart from the scar formation, intratubular calcifications, IGCNU, a lymphoplasmacytic infiltrate, hemosiderin-containing macrophages, and testicular atrophy (Figure 22) ${ }^{130-132}$ In many cases, the scarred focus still has residual, hyalinized tubular outlines, which therefore should not be misconstrued as evidence for a non-neoplastic scarring process. It is likely that such tubular remnants within scars reflect regression of intertubular growth of pre-existing germ cell tumor, a relatively frequent focal pattern in seminoma. That the scarring represents 'burnt-out' neoplasm is supported by the fact that in many cases there is residual, viable tumor that is focally or extensively undergoing this retrogressive, scarring process. While choriocarcinoma is probably the tumor that is most prone to spontaneous regression, seminoma is also susceptible and is responsible for the greatest number of cases, given its much greater frequency. This phenomenon may also be seen with embryonal carcinoma in which instance coarse intratubular calcification may be a clue to the prior presence of viable neoplasia of that type.

\section{Acknowledgement}

I thank Dr Robert H Young for his careful review of the manuscript and his helpful suggestions.

\section{References}

1 Katsube Y, Berg JW, Silverberg SG. Epidemiologic pathology of ovarian tumors: a histopathologic review of primary ovarian neoplasms diagnosed in the
Denver standard metropolitan statistical area, 1 July-31 December 1969 and 1 July-31 December 1979. Int J Gynecol Pathol 1982;1:3-16.

2 Koonings PP, Campbell K, Mishell Jr DR, et al. Relative frequency of primary ovarian neoplasms: a 10-year review. Obstet Gynecol 1989;74:921-926.

3 von Hochstetter AR, Hedinger CE. The differential diagnosis of testicular germ cell tumors in theory and practice: a critical analysis of two major systems of classification and review of 389 cases. Virchows Arch [A] 1982;396:247-277.

4 Jacobsen GK, Barlebo H, Olsen J, et al. Testicular germ cell tumours in Denmark 1976-1980. Pathology of 1058 consecutive cases. Acta Radiol Oncol 1984; 23:239-247.

5 Kurman RJ, Norris HJ. Malignant mixed germ cell tumors of the ovary: a clinical and pathologic analysis of 30 cases. Obstet Gynecol 1976;48:579-589.

6 Scully RE, Young RH, Clement PB. Tumors of the Ovary, Maldeveloped Gonads, Fallopian Tube and Broad Ligament. Atlas of Tumor Pathology, Fascicle 23, Third Series. Armed Forces Institute of Pathology: Washington, DC, 1998.

7 Leibovitch I, Foster RS, Ulbright TM, et al. Adult primary pure teratoma of the testis. The Indiana experience. Cancer 1995;75:2244-2250.

8 Simmonds PD, Lee AH, Theaker JM, et al. Primary pure teratoma of the testis. J Urol 1996;155:939-942.

9 Sesterhenn IA, Mesonero C, Davis CJ, et al. Testicular teratomas in adults. Histopathology 2002;41(Suppl 1):24.

10 Patil SR, Kaiser-McGaw B, Hecht F, et al. Human benign ovarian teratomas: chromosomal and electrophoretic enzyme studies. Birth Defects Orig Artic Ser 1978;14:297-301.

11 Surti U, Hoffner L, Chakravarti A, et al. Genetics and biology of human ovarian teratomas. I. Cytogenetic analysis and mechanism of origin. Am J Hum Genet 1990;47:635-643.

12 Castedo SM, de Jong B, Oosterhuis JW, et al. Chromosomal changes in mature residual teratomas following polychemotherapy. Cancer Res 1989; 49: 672-676.

13 Gibas Z, Prout GR, Pontes JE, et al. Chromosome changes in germ cell tumors of the testis. Cancer Genet Cytogenet 1986;19:245-252.

14 Looijenga LH, Oosterhuis JW, Ramaekers FC, et al. Dual parameter flow cytometry for deoxyribonucleic acid and intermediate filament proteins of residual mature teratoma. All tumor cells are aneuploid. Lab Invest 1991;64:113-117.

15 Samaniego F, Rodriguez E, Houldsworth J, et al. Cytogenetic and molecular analysis of human male germ cell tumors: chromosome 12 abnormalities and gene amplification. Genes Chrom Cancer 1990;1:289-300.

16 van Echten J, van der Vloedt WS, van de Pol M, et al. Comparison of the chromosomal pattern of primary testicular nonseminomas and residual mature teratomas after chemotherapy. Cancer Genet Cytogenet 1997;99:59-67.

17 Vortmeyer AO, Devouassoux-Shisheboran M, Li G, et al. Microdissection-based analysis of mature ovarian teratoma. Am J Pathol 1999;154:987-991.

18 Linder D, Kaiser-McGaw B, Hecht F. Parthenogenetic origin of benign ovarian teratomas. N Engl J Med 1975;292:63-66.

19 Kernek KM, Ulbright TM, Zhang S, et al. Identical allelic loss in mature teratoma and different histo- 
logic components of malignant mixed germ cell tumors of the testis. Am J Pathol 2003;163:2477-2484.

20 Tanner CO. Tumors of the testicle. Surg Gynecol Obstet 1922;35:565-572.

21 Manivel JC, Reinberg Y, Niehans GA, et al. Intratubular germ cell neoplasia in testicular teratomas and epidermoid cysts. Correlation with prognosis and possible biologic significance. Cancer 1989;64:715-720.

22 Kallenberg GA, Pesce CM, Norman B, et al. Ectopic hyperprolactinemia resulting from an ovarian teratoma. JAMA 1990;262:2472-2474.

23 Palmer PE, Bogojavlensky S, Bhan AK, et al. Prolactinoma in wall of ovarian dermoid cyst with hyperprolactinemia. Obstet Gynecol 1990;75:540-542.

24 Halabi M, Oliva E, Mazal PR, et al. Prostatic tissue in mature cystic teratomas of the ovary: a report of four cases, including one with features of prostatic adenocarcinoma, and cytogenetic studies. Int J Gynecol Pathol 2002;21:261-267.

25 Unger PD, Cohen EL, Talerman A. Mixed germ cell tumor of the testis: a unique combination of seminoma and teratoma composed predominantly of prostatic tissue. J Urol Pathol 1998;9:257-263.

26 Ulbright TM, Amin MB, Young RH. Atlas of Tumor Pathology: Tumors of the Testis, Adenexa, Spermatic Cord and Scrotum, Third series. Armed Forces Institute of Pathology: Washington, DC, 1999.

27 Allen EA, Burger PC, Epstein JI. Microcystic meningioma arising in a mixed germ cell tumor of the testis: a case report. Am J Surg Pathol 1999;23:1131-1135.

28 Grady RW, Ross JH, Kay R. Epidemiological features of testicular teratoma in a prepubertal population. J Urol 1997;158:1191-1192.

29 Kashiwagi A, Nagamori S, Toyota K, et al. DNA ploidy of testicular germ cell tumors in childhood; difference from adult testicular tumors. Nippon Hinyokika Gakkai Zasshi 1993;84:1655-1659 (in Japanese).

30 Bussey KJ, Lawce HJ, Olson SB, et al. Chromosome abnormalities of eighty-one pediatric germ cell tumors: sex-, age-, site-, and histopathology-related differences-a Children's Cancer Group study. Genes Chromosomes Cancer 1999;25:134-146.

31 Mostert M, Rosenberg C, Stoop H, et al. Comparative genomic and in situ hybridization of germ cell tumors of the infantile testis. Lab Invest 2000;80:1055-1064.

32 Hawkins EP, Hicks MJ. Solid tumors and germ cell tumors induce nonneoplastic germ cell proliferations in testes of infants and young children. Hum Pathol 1998;29:1547-1548.

33 Stamp IM, Jacobsen GK. Infant intratubular germ cell neoplasia. Am J Surg Pathol 1995;19:489.

34 Younger C, Ulbright TM, Zhang S, et al. Molecular evidence supporting the neoplastic nature of some epidermoid cysts of the testis. Arch Pathol Lab Med 2003;127:858-860.

35 Ulbright TM, Srigley JR. Dermoid cyst of the testis: a study of five postpubertal cases, including a pilomatrixoma-like variant, with evidence supporting its separate classification from mature testicular teratoma. Am J Surg Pathol 2001;25:788-793.

36 Price Jr EB. Epidermoid cysts of the testis: a clinical and pathologic analysis of 69 cases from the testicular tumor registry. J Urol 1969;102:708-713.

37 Young RH, Prat J, Scully RE. Epidermoid cyst of the ovary. A report of three cases with comments on histogenesis. Am J Clin Pathol 1980;73:272-276.
38 Dieckmann KP, Loy V. Epidermoid cyst of the testis a review of clinical and histogenetic considerations. Br J Urol 1994;73:436-441.

39 Ayhan A, Bukulmez O, Genc C, et al. Mature cystic teratomas of the ovary: case series from one institution over 34 years. Eur J Obstet Gynecol Reprod Biol 2000;88:153-157.

40 Comerci Jr JT, Licciardi F, Bergh PA, et al. Mature cystic teratoma: a clinicopathologic evaluation of 517 cases and review of the literature. Obstet Gynecol 1994;84:22-28.

41 Hirakawa T, Tsuneyoshi M, Enjoji M. Squamous cell carcinoma arising in mature cystic teratoma of the ovary. Clinicopathologic and topographic analysis. Am J Surg Pathol 1989;13:397-405.

42 Peterson WF. Malignant degeneration of benign cystic teratomas of the ovary: collective review of the literature. Obstet Gynecol Surv 1957;12:793-830.

43 Davis GL. Malignant melanoma arising in mature ovarian cystic teratoma (dermoid cyst). Report of two cases and literature analysis. Int J Gynecol Pathol 1996;15:356-362.

44 Sumi T, Ishiko O, Yoshida $\mathrm{H}$, et al. Expression of cyclooxygenase-2 in ovarian mature cystic teratomas with malignant transformation. Int J Mol Med 2001; 8:495-498.

45 Noumoff JS, LiVolsi VA, Deger RB, et al. Chromosome analysis and comparison of the benign cystic and malignant squamous component of an ovarian teratoma. Cancer Genet Cytogenet 2001;125:59-62.

46 Thurlbeck WM, Scully RE. Solid teratoma of the ovary: a clinicopathologic analysis of 9 cases. Cancer 1960;13:804-811.

47 Norris HJ, Zirkin HJ, Benson WL. Immature (malignant) teratoma of the ovary: a clinical and pathologic study of 58 cases. Cancer 1976;37:2359-2372.

48 O'Connor DM, Norris HJ. The influence of grade on outcome of stage I ovarian immature (malignant) teratomas and the reproducibility of grading. Int J Gynecol Pathol 1994;13:283-289.

49 Heifetz SA, Cushing B, Giller R, et al. Immature teratomas in children: pathologic considerations: a report from the combined Pediatric Oncology Group/ Children's Cancer Group. Am J Surg Pathol 1998;22: 1115-1124.

50 Marina NM, Cushing B, Giller R, et al. Complete surgical excision is effective treatment for children with immature teratomas with or without malignant elements: A Pediatric Oncology Group/Children's Cancer Group Intergroup Study. J Clin Oncol 1999; 17:2137-2143.

51 Robboy SJ, Scully RE. Ovarian teratoma with glial implants on the peritoneum. Hum Pathol 1970;1: 643-653.

52 Nielsen SN, Scheithauer BW, Gaffey TA. Gliomatosis peritonei. Cancer 1985;56:2499-2503.

53 Ferguson AW, Katabuchi H, Ronnett BM, et al. Glial implants in gliomatosis peritonei arise from normal tissue, not from the associated teratoma. Am J Pathol 2001;159:51-55.

54 Kwan M-Y, Kalle W, Lau GTC, et al. Is gliomatosis peritonei derived from the associated ovarian teratoma? Hum Pathol 2004;35:685-688.

55 Yanai-Inbar I, Scully RE. Relation of ovarian dermoid cysts and immature teratomas: an analysis of 350 cases of immature teratoma and 10 cases of dermoid 
cyst with microscopic foci of immature tissue. Int J Gynecol Pathol 1987;6:203-212.

56 Kraggerud SM, Szymanska J, Abeler VM, et al. DNA copy number changes in malignant ovarian germ cell tumors. Cancer Res 2000;60:3025-3030.

57 Ihara T, Ohama K, Satoh H, et al. Histologic grade and karyotype of immature teratoma of the ovary. Cancer 1984;54:2988-2994.

58 Kleinman GM, Young RH, Scully RE. Primary neuroectodermal tumors of the ovary: a report of 25 cases. Am J Surg Pathol 1993;17:764-778.

59 Aguirre P, Scully RE. Malignant neuroectodermal tumor of the ovary, a distinctive form of monodermal teratoma: report of five cases. Am J Surg Pathol 1982;6:283-292.

60 Michael H, Hull MT, Ulbright TM, et al. Primitive neuroectodermal tumors arising in testicular germ cell neoplasms. Am J Surg Pathol 1997;21:896-904.

61 Michael H, Hull MT, Foster RS, et al. Nephroblastoma-like tumors in patients with testicular germ cell tumors. Am J Surg Pathol 1998;22:1107-1114.

62 Szyfelbein WM, Young RH, Scully RE. Struma ovarii simulating ovarian tumors of other types. A report of 30 cases. Am J Surg Pathol 1995;19:21-29.

63 Szyfelbein WM, Young RH, Scully RE. Cystic struma ovarii: a frequently unrecognized tumor. A report of 20 cases. Am J Surg Pathol 1994;18:785-788.

64 Devaney K, Snyder R, Norris HJ, et al. Proliferative and histologically malignant struma ovarii: a clinicopathologic study of 54 cases. Int J Gynecol Pathol 1993;12:333-343.

65 Berdjis CC, Mostofi FK. Carcinoid tumors of the testis. J Urol 1977;118:777-782.

66 Reyes A, Moran CA, Suster S, et al. Neuroendocrine carcinomas (carcinoid tumor) of the testis. A clinicopathologic and immunohistochemical study of ten cases. Am J Clin Pathol 2003;120:182-187.

67 Robboy SJ, Scully RE, Norris HJ. Primary trabecular carcinoid of the ovary. Obstet Gynecol 1977;49:202-207.

68 Robboy SJ, Norris HJ, Scully RE. Insular carcinoid primary in the ovary. A clinicopathologic analysis of 48 cases. Cancer 1975;36:404-418.

69 Robboy SJ, Scully RE, Norris HJ. Carcinoid metastatic to the ovary. A clinocopathologic analysis of 35 cases. Cancer 1974;33:798-811.

70 Robboy SJ, Scully RE. Strumal carcinoid of the ovary: an analysis of 50 cases of a distinctive tumor composed of thyroid tissue and carcinoid. Cancer 1980;46:2019-2034.

71 Baker PM, Oliva E, Young RH, et al. Ovarian mucinous carcinoids including some with a carcinomatous component: a report of 17 cases. Am J Surg Pathol 2001;25:557-568.

72 Damjanov I, Niejadlik DC, Rabuffo JV, et al. Cribriform and sclerosing seminoma devoid of lymphoid infiltrates. Arch Pathol Lab Med 1980;104:527-530.

73 Jacobsen GK, von der Maase H, Specht L, et al. Histopathological features in stage I seminoma treated with orchidectomy only. J Urol Pathol 2003;3:85-94.

74 Looijenga LH, Stoop H, de Leeuw HP, et al. POU5F1 (OCT3/4) identifies cells with pluripotent potential in human germ cell tumors. Cancer Res 2003; 63:2244-2250.

75 Jones TD, Ulbright TM, Eble JN, et al. OCT4 staining in testicular tumors: a sensitive and specific marker for seminoma and embryonal carcinoma. Am J Surg Pathol 2004;28:935-940.
76 Young RH, Finlayson N, Scully RE. Tubular seminoma. Report of a case. Arch Pathol Lab Med 1989;113:414-416.

77 Zavala-Pompa A, Ro JY, El-Naggar AK, et al. Tubular seminoma. An immunohistochemical and DNA flowcytometric study of four cases. Am J Clin Pathol 1994;102:397-401.

78 Rishi M, Howard LN, Bratthauer GL, et al. Use of monoclonal antibody against inhibin as a marker for sex cord-stromal tumors of the ovary. Am J Surg Pathol 1997;21:583-589.

79 Iczkowski KA, Bostwick DG, Roche PC, et al. Inhibin $A$ is a sensitive and specific marker for testicular sex cord-stromal tumors. Mod Pathol 1998;11:774-779.

80 Kommoss F, Oliva E, Bittinger F, et al. Inhibin-alpha CD99, HEA125, PLAP, and chromogranin immunoreactivity in testicular neoplasms and the androgen insensitivity syndrome. Hum Pathol 2000;31:10551061.

81 Henley JD, Young RH, Wade CL, et al. Seminomas with exclusive intertubular growth: a report of 12 clinically and grossly inconspicuous tumors. Am J Surg Pathol 2004;28:1163-1168.

82 Tickoo SK, Hutchinson B, Bacik J, et al. Testicular seminoma: a clinicopathologic and immunohistochemical study of 105 cases with special reference to seminomas with atypical features. Int J Surg Pathol 2002;10:23-32.

83 Mostofi FK, Sesterhenn IA. Pathology of germ cell tumors of testes. Prog Clin Biol Res 1985;203:1-34.

84 von Hochstetter AR, Sigg C, Saremaslani P, et al. The significance of giant cells in human testicular seminomas. A clinico-pathological study. Virchows Arch [A] 1985;407:309-322.

85 Herrington JBI, Scully RE. Endocrine aspects of germ cell tumors. In: Damjanov I, Solter D, Knowles B (eds). The Human Teratomas. Humana Press: Totowa, NJ, 1983, pp 215-229.

86 Clement PB, Young RH, Scully RE. Clinical syndromes associated with tumors of the female genital tract. Semin Diagn Pathol 1991;8:204-233.

87 Giralt S, Dexeus F, Amato R, et al. Hyperthyroidism in men with germ cell tumors and high levels of betahuman chorionic gonadotropin. Cancer 1992; 69: 1286-1290.

88 da Silva MA, Edmondson JW, Eby C, et al. Humoral hypercalcemia in seminomas. Med Pediatr Oncol 1992;20:38-41.

89 Srivastava KP. Hypoglycemia associated with nonpancreatic mesenchymal tumors. Int Surg 2004; 61: 282-286.

90 Mann AS. Bilateral exophthalmos in seminoma. J Clin Endocrinol Metab 1967;27:1500-1502.

91 Taylor JB, Solomon DH, Levine RE, et al. Exophthalmos in seminoma: regression with steroids and orchiectomy. JAMA 1978;240:860-861.

92 Burton GV, Bullard DE, Walther PJ, et al. Paraneoplastic encephalopathy with testicular carcinoma: a reversible neurologic syndrome. Cancer 1988; 62: 2248-2251.

93 Voltz R, Gultekin SH, Rosenfeld MR, et al. A serologic marker of paraneoplastic limbic and brain-stem encephalitis in patients with testicular cancer. N Engl J Med 1999;340:1788-1795.

94 Masson P. Etude sur le seminome. Rev Canad Biol 1946;5:361-387. 
95 Rosai J, Silber I, Khodadoust K. Spermatocytic seminoma. I. Clinicopathologic study of six cases and review of the literature. Cancer 1969;24:92-102.

96 Scully RE. Spermatocytic seminoma of the testis: a report of 3 cases and review of the literature. Cancer 1961;14:788-794.

97 Eble JN. Spermatocytic seminoma. Hum Pathol 1994; 25:1035-1042.

98 Talerman A. Spermatocytic seminoma: clinicopathological study of 22 cases. Cancer 1980;45:2169-2176.

99 Albores-Saavedra J, Huffman H, Alvarado-Cabrero I, et al. Anaplastic variant of spermatocytic seminoma. Hum Pathol 1996;27:650-655.

100 Skakkebaek NE, Berthelsen JG, Giwercman A, et al. Carcinoma-in-situ of the testis: possible origin from gonocytes and precursor of all types of germ cell tumours except spermatocytoma. Int $\mathrm{J}$ Androl 1987;10:19-28.

101 Dekker I, Rozeboom T, Delemarre J, et al. Placentallike alkaline phosphatase and DNA flow cytometry in spermatocytic seminoma. Cancer 1992;69:993-996.

102 Cummings OW, Ulbright TM, Eble JN, et al. Spermatocytic seminoma: an immunohistochemical study. Hum Pathol 1994;25:54-59.

103 Hittmair A, Rogatsch H, Hobisch A, et al. CD30 expression in seminoma. Hum Pathol 1996;27: 1166-1171.

104 Kraggerud SM, Berner A, Bryne M, et al. Spermatocytic seminoma as compared to classical seminoma: an immunohistochemical and DNA flow cytometric study. APMIS 1999;107:297-302.

105 Floyd C, Ayala AG, Logothetis CJ, et al. Spermatocytic seminoma with associated sarcoma of the testis. Cancer 1988;61:409-414.

106 True LD, Otis CN, Delprado W, et al. Spermatocytic seminoma of testis with sarcomatous transformation. A report of five cases. Am J Surg Pathol 1988;12:75-82.

107 Kurman RJ, Norris HJ. Embryonal carcinoma of the ovary: a clinicopathologic entity distinct from endodermal sinus tumor resembling embryonal carcinoma of the adult testis. Cancer 1976;38:2420-2433.

108 Grady RW, Ross JH, Kay R. Patterns of metastatic spread in prepubertal yolk sac tumor of the testis. J Urol 1995;153:1259-1261.

109 Teilum G. Classification of endodermal sinus tumor (mesoblastoma vitellinum) and so-called 'embryonal carcinoma' of the ovary. Acta Pathol Microbiol Scand 1965;64:407-429.

110 Teilum G. Special Tumors of Ovary and Testis and Related Extragonadal Lesions. J. B. Lippincott: Philadelphia, 1976.

111 Teilum G. 'Mesonephroma ovarii' (Schiller)—an extra-embryonic mesoblastoma of germ cell origin in the ovary and the testis. Acta Pathol Microbiol Scand 1950;27:249-261.

112 Teilum G. Endodermal sinus tumors of the ovary and testis: comparative morphogenesis of the so-called mesonephroma ovarii (Schiller) and extraembryonic (yolk sac-allantoic) structures of the rat's placenta. Cancer 1959;12:1092-1105.

113 Zirker TA, Silva EG, Morris M, et al. Immunohistochemical differentiation of clear-cell carcinoma of the female genital tract and endodermal sinus tumor with the use of alpha-fetoprotein and Leu-M1. Am J Clin Pathol 1989;91:511-514.

114 Henley JD, Michael H, Young RH, et al. Solid pattern yolk sac tumor of the testis: a histologic and immunohistochemical study of 9 cases. Lab Invest 2003;83:153A

115 Ulbright TM, Roth LM, Brodhecker CA. Yolk sac differentiation in germ cell tumors. A morphologic study of 50 cases with emphasis on hepatic, enteric, and parietal yolk sac features. Am J Surg Pathol 1986;10:151-164

116 Clement PB, Young RH, Scully RE. Endometrioid-like variant of ovarian yolk sac tumor. A clinicopathological analysis of eight cases. Am J Surg Pathol 1987;11:767-778.

117 Michael H, Lucia J, Foster RS, et al. The pathology of late recurrence of testicular germ cell tumors. Am J Surg Pathol 2000;24:257-273.

118 Nogales FF, Bergeron C, Carvia RE, et al. Ovarian endometrioid tumors with yolk sac tumor component, an unusual form of ovarian neoplasm. Analysis of six cases. Am J Surg Pathol 1996;20:1056-1066.

119 Niehans GA, Manivel JC, Copland GT, et al. Immunohistochemistry of germ cell and trophoblastic neoplasms. Cancer 1988;62:1113-1123.

120 Ramalingam P, Malpica A, Silva EG, et al. The use of cytokeratin 7 in differentiating yolk sac tumors from endometrioid and clear cell carcinomas of the ovary. Mod Pathol 2003;16:207A.

121 Nakashima N, Fukatsu T, Nagasaka T, et al. The frequency and histology of hepatic tissue in germ cell tumors. Am J Surg Pathol 1987;11:682-692.

122 Prat J, Bhan AK, Dickersin GR, et al. Hepatoid yolk sac tumor of the ovary (endodermal sinus tumor with hepatoid differentiation): a light microscopic, ultrastructural and immunohistochemical study of seven cases. Cancer 1982;50:2355-2368.

123 Devouassoux-Shisheboran M, Schammel DP, Tavassoli FA. Ovarian hepatoid yolk sac tumours: morphological, immunohistochemical and ultrastructural features. Histopathology 1999;34:462-469.

124 Ishikura H, Scully RE. Hepatoid carcinoma of the ovary. A newly described tumor. Cancer 1987; 60: 2775-2784.

125 Damjanov I, Amenta PS, Zarghami F. Transformation of an AFP-positive yolk sac carcinoma into an AFPnegative neoplasm: evidence for in vivo cloning of the human parietal yolk sac carcinoma. Cancer 1984; 53:1902-1907

126 Evans RW. Developmental stages of embryo-like bodies in teratoma testis. J Clin Pathol 1957;10:31-39.

127 Prat J, Matias-Guiu X, Scully RE. Hepatic yolk sac differentiation in an ovarian polyembryoma. Surg Pathol 1989;2:147-150.

128 Peyron A. Faits nouveaux relatifs à l'origine et à l'histogenèse des embryomes. Bull Assoc Franc Cancer 1939;28:658-681.

129 Young RH, Scully RE. Testicular Tumors. ASCP Press: Chicago, 1990.

130 Bär W, Hedinger C. Comparison of histologic types of primary testicular germ cell tumors with their metastases: consequences for the WHO and the British Nomenclatures? Virchows Arch [A] 1976; 370:41-54.

131 Azzopardi JG, Mostofi FK, Theiss EA. Lesions of testes observed in certain patients with widespread choriocarcinoma and related tumors. Am J Pathol 1961;38:207-225.

132 Balzer BL, Ulbright TM. Spontaneous regression of testicular germ cell tumors: a study of 42 cases. Mod Pathol 2004;17(Suppl 1):140A (Abstract). 